\title{
Chapter 2 \\ Civil Protection Achievements and Critical \\ Issues in Seismology and Earthquake \\ Engineering Research
}

\author{
Mauro Dolce and Daniela Di Bucci
}

\begin{abstract}
A great complexity characterizes the relationships between science and civil protection. Science attains advances that can allow civil protection organizations to make decisions and undertake actions more and more effectively. Provided that these advances are consolidated and shared by a large part of the scientific community, civil protection has to take them into account in its operational procedures and in its decision-making processes, and it has to do this while growing side by side with the scientific knowledge, avoiding any late pursuit.

The aim of the paper is to outline the general framework and the boundary conditions, to describe the overall model of such relationships and the current stateof-the-art, focusing on the major results achieved in Italy and on the many criticalities, with special regards to research on seismic risk.

Among the boundary conditions, the question of the different roles and responsibilities in the decision-making process will be addressed, dealing in particular with the contribution of scientists and decision-makers, among the others, in the risk management. In this frame, the different kinds of contributions that civil protection receives from the scientific community will be treated. Some of them are directly planned, asked and funded by civil protection. Some contributions come instead from research that the scientific community develops in other frameworks. All of them represent an added value from which civil protection wants to take advantage, but only after a necessary endorsement by a large part of the scientific community and an indispensable adaptation to civil protection utilization. This is fundamental in order to avoid that any decision and any consequent action, which could in principle affect the life and property of many citizens, be undertaken on the basis of non-consolidated and/or minor and/or not shared scientific achievements.
\end{abstract}

\footnotetext{
M. Dolce $(\varangle) \cdot$ D. Di Bucci

Department of Civil Protection, Presidency of the Council of Ministers, Rome, Italy

e-mail: mauro.dolce@protezionecivile.it; daniela.dibucci@protezionecivile.it
}

A. Ansal (ed.), Perspectives on European Earthquake Engineering and Seismology, Geotechnical, Geological and Earthquake Engineering 39,

DOI 10.1007/978-3-319-16964-4_2 


\subsection{Introduction}

In the last decade, within their activities at the Italian Department of Civil Protection (DPC), the authors had the opportunity to contribute to develop the relationships between the "Civil Protection" and the "Scientific Community", especially in the field of seismic and seismo-induced risks.

During these years, the DPC has faced difficult circumstances, not only in emergency situations, which have required strong and continuous interactions with the scientific community. As it can be easily understood in theory, but much less easily in practice, the civil protection approach to seismic risk problems is strongly different from the research approach, although important synergies could arise from a cooperation and a reciprocal understanding. From the DPC point of view, there are many good reasons for a close connection between civil protection and research, e.g.: the opportunity to reach a scientific consensus on evaluations that imply wide uncertainties; a better management of the resource allocation for risk mitigation; the possibility to make precise and rapid analyses for fast and effective emergency actions; the optimization of resources and actions for the emergency overcoming. There are of course positive implications also for the scientific community, such as, for instance: a clear finalization of the research activities; wider investigation perspectives, too often strictly focused on the achievement of specific academic advancements; the ethical value of a research that has direct and positive social implications (Dolce 2008).

Creating a fruitful connection between the two parts implies a continuous and dynamic adaptation to the different ways of thinking about how to solve problems. This involves different fields: the language first of all, including the reciprocal and outward communication, then the timing for the response, the budget available, the right balance among the different stakeholders, the scientific consensus on the most significant achievements and, ultimately, the responsibilities.

A great complexity generally characterizes the relationships between science and civil protection. As will be shown in the following sections, science attains advances that can allow civil protection organizations to make decisions and undertake actions more and more effectively. Provided that these advances are consolidated and shared by a large part of the scientific community, civil protection has to take them into account in its operational procedures and in its decisionmaking processes, and it has to do this while growing side by side with the scientific knowledge, avoiding any late pursuit.

Such a complexity is summarized in the scheme of Fig. 2.1, which also represents the backbone of this paper. The aim of the work here presented, indeed, is to outline the framework and the boundary conditions, to show the overall model of such relationships and to describe the current state-of-the-art, focusing on the major results achieved in Italy and on the many criticalities that still remain to be solved.

Among the boundary conditions, the question of the different roles and responsibilities in the decision-making process will be addressed, dealing in particular 


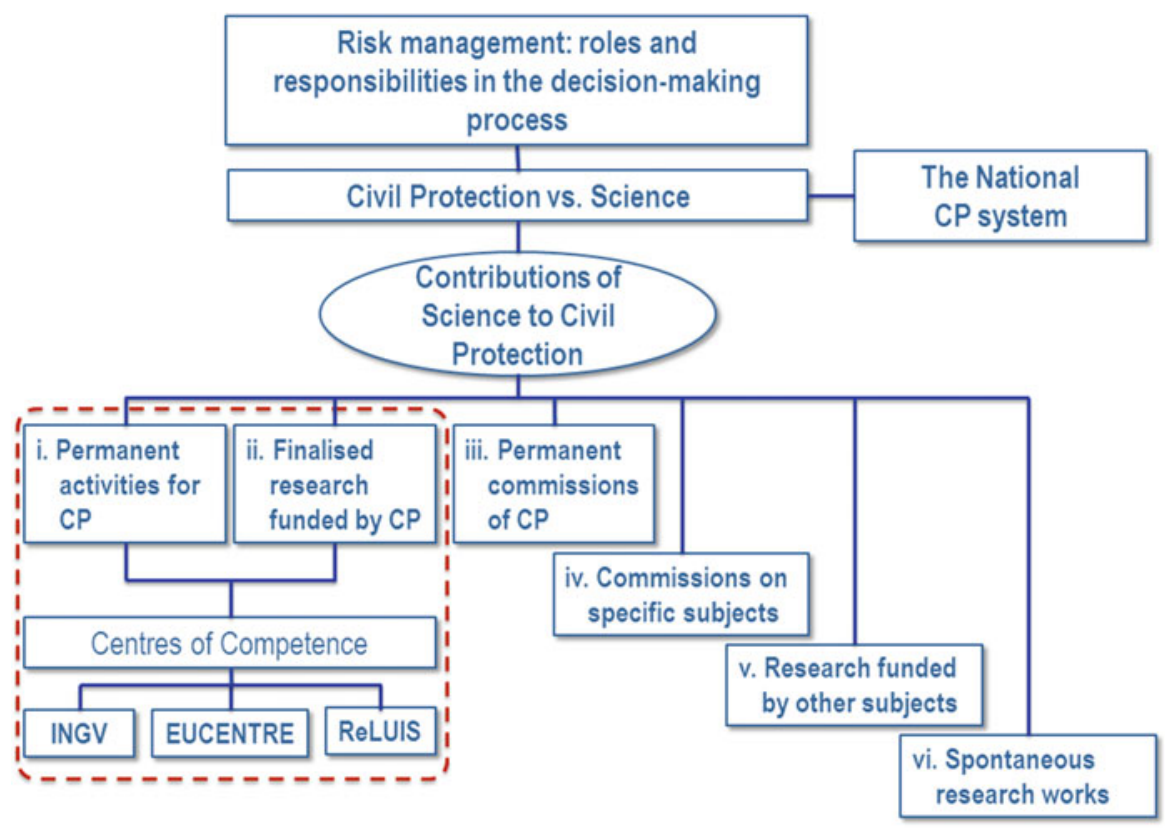

Fig. 2.1 Chart of the relationships between civil protection and science

with the contribution of scientists and decision-makers, among the others, in the risk management. In this frame, and given the specific organization of the civil protection system in Italy, which is the cradle of the experience here presented, the different kinds of contributions that civil protection receives from the scientific community will then be treated. The collection of these contributions follows different paths. Some of them are directly planned, asked and funded by civil protection, although with a different commitment for the scientific institutions or commissions involved, which especially regards their activity field and the related duration through times (points $i$ to iv in Fig. 2.1). Some contributions come instead from research that the scientific community develops in other frameworks: European projects, Regional funds, etc. (points v to vi in Fig. 2.1). All of them represent an added value from which civil protection wants to take advantage for sure, but only after a necessary endorsement by a large part of the scientific community and an indispensable adaptation to civil protection utilization. This is fundamental in order to avoid that any decision and any consequent action, which could in principle affect the life and property of many citizens, be undertaken on the basis of non-consolidated and/or minor and/or not shared scientific achievements. 
Table 2.1 Points of view of scientists and decision-makers

\begin{tabular}{l|l}
\hline Scientists & Decision-makers \\
\hline $\begin{array}{l}\text { Frequently model events that occurred in the } \\
\text { past in order to understand their dynamics }\end{array}$ & $\begin{array}{l}\text { Need well-tested models, which are able to } \\
\text { describe events possibly occurring in the future }\end{array}$ \\
\hline $\begin{array}{l}\text { Follow a scientific approach to the risks that } \\
\text { is often probabilistic, and always affected by } \\
\text { uncertainties }\end{array}$ & $\begin{array}{l}\text { In most cases are asked to make decisions that } \\
\text { necessarily require a yes or no answer }\end{array}$ \\
\hline $\begin{array}{l}\text { Need a relatively long time for their work, in } \\
\text { order to acquire more data trying to reduce } \\
\text { uncertainties, preferring to wait rather than to } \\
\text { be wrong }\end{array}$ & $\begin{array}{l}\text { Are generally asked to give an immediate } \\
\text { response, often balancing low occurrence prob- } \\
\text { abilities versus envisaged catastrophic } \\
\text { consequences }\end{array}$ \\
\hline $\begin{array}{l}\text { Exert the "art of doubt" } \\
\begin{array}{l}\text { Estimate the costs to carry out their best } \\
\text { research }\end{array}\end{array}$ & Need solutions \\
\hline
\end{tabular}

\subsection{Roles and Responsibilities in the Decision-Making Process}

\subsubsection{Scientists and Decision-Makers in the Risk Management}

Scientists and decision-makers are often considered as two counterparts which dynamically interact in the decision-making process. As a matter of fact, within the civil protection system, they represent two different points of view that have to be continuously reconciled (Dolce and Di Bucci 2014), as summarized in Table 2.1.

A further complexity is noticeable, especially in civil protection activities, i.e., the roles and the responsibilities of decision-makers at the different levels of the decisional process. One should discriminate between political decision-makers (PDMs) and technical decision-makers (TDMs). Moreover, PDMs operate in relation to either general risk management policies or specific scenarios. Indeed, a further and more subtle distinction could be made (Bretton 2014) between politicians and policy makers. Nevertheless, for the sake of simplicity, only three categories, i.e., scientists, PDMs, and TDMs, will be referred hereinafter as the three main actors in the decisional chain.

There is no doubt that in many cases it can be hard to totally separate the contribution of each of them, since some feedback and interactions are often necessary. However, in every step of an ideal decision-making process, each of these actors should play a primary role, as summarized in Table 2.2.

These sophisticated links and interactions can obviously cause distortions in the roles to be played, and thus in the responsibilities to be taken. This can further happen if the participants in the decisional process do not, or cannot, accomplish their tasks or if, for various reasons, they go beyond the limits of their role.

Scientists, for instance, could either:

- not provide fully quantitative evaluations;

- miss to supply scientific support in cost-benefit analyses;

- give undue advice concerning civil protection actions. 
Table 2.2 Steps of an ideal decision-making process, and role virtually played by the different participants

\begin{tabular}{|c|c|c|c|c|}
\hline Step & Description & Scientists & PDMs & TDMs \\
\hline 1 & $\begin{array}{l}\text { definition of the acceptable level of risk according to } \\
\text { established policy (i.e., in a probabilistic framework, of } \\
\text { the acceptable probability of occurrence of quantitatively } \\
\text { estimated consequences for lives and property) }\end{array}$ & $\mathrm{x}$ & $X$ & \\
\hline 2 & allocation of proper budget for risk mitigation & & $X$ & $\mathrm{x}$ \\
\hline 3 & $\begin{array}{l}\text { quantitative evaluation of the risk (considering hazard, } \\
\text { vulnerability, and exposure) }\end{array}$ & $X$ & & $\mathrm{x}$ \\
\hline 4 & $\begin{array}{l}\text { identification of specific actions capable of reducing the } \\
\text { risk to the acceptable level }\end{array}$ & & & $X$ \\
\hline 5 & $\begin{array}{l}\text { cost-benefit evaluation of the possible risk-mitigating } \\
\text { actions }\end{array}$ & $X$ & & $\mathrm{x}$ \\
\hline 6 & $\begin{array}{l}\text { adoption of the most suitable technical solution, according } \\
\text { to points } 1,4 \text {, and } 5\end{array}$ & $\mathrm{x}$ & $\mathrm{x}$ & $X$ \\
\hline 7 & implementation of risk-mitigating actions & & & $X$ \\
\hline
\end{tabular}

PDMs political decision-makers, TDMs technical decision-makers, $X$ primary role, $x$ occasional support

PDMs could:

- decide not to establish the acceptable risk levels for the community they represent;

- prefer to state that a "zero" risk solution must be pursued, which is in fact a non-decision;

- not allocate an adequate budget for risk mitigation.

TDMs could tend (or could be forced, in emergency conditions) to make and implement decisions they are not in charge for, because of the lack of:

- scientific quantitative evaluations;

- acceptable risk statements (or impossibility to get them);

- budget.

A number of examples of individuals usurping or infringing on roles not assigned to them in the decisional process is reported by Dolce and Di Bucci (2014).

\subsubsection{Other Actors in the Decision Process}

Other actors, besides scientists and decision makers, play an important role in the risk cycle management; among them mass media, judiciary, and citizens deserve to be especially mentioned, because their behaviours can strongly affect the decisionmaking process. 
Table 2.3 Pros and cons for civil protection in the mass media behaviour

\begin{tabular}{l|l}
\hline Pros & Cons \\
\hline $\begin{array}{l}\text { Spreading knowledge about risks and their } \\
\text { reduction in order to increase people's awareness } \\
\text { on risks }\end{array}$ & $\begin{array}{l}\text { Distortion of information due to incompe- } \\
\text { tence or to commercial or political purposes }\end{array}$ \\
\hline $\begin{array}{l}\text { Disseminating best practices on behaviours to be } \\
\text { adopted both in ordinary and in emergency } \\
\text { conditions }\end{array}$ & $\begin{array}{l}\text { Accreditation of non-scientific ideas and } \\
\text { non-expert opinions }\end{array}$ \\
\hline Spreading civil protection alerts & Spreading false alarms \\
\hline
\end{tabular}

Dealing with the communication of civil protection matters to the public through the media, it is worth mentioning Franco Gabrielli, the Head of the Italian Department of Civil Protection since 2010. He well summarized the complexity of this issue when he affirmed that "We have the duty of communicating with citizens, but we are voiceless and invisible if we don't pass through the «cultural mediation» of the information channels and their managers. Maybe we have neither analysed deeply enough the consequences of such mediation, nor we have learned well enough to avoid traps and to take the possible advantages" (Gabrielli 2013).

As a matter of fact, the importance of mass media (newspapers, radio, television, as well as web and social networks) is quickly increasing in any field and, therefore, also in risk management. There is a great need for an effective collaboration between civil protection TDMs and the media. It can determine the advantages summarized in the left-hand-side of Table 2.3 and, in the meanwhile, could reduce some of the problems reported in the right-hand-side of the same table, mostly induced by the need that media have to increase their audience for commercial purposes, or to support some political orientations.

Two points, well established since long time by the theories of mass communication, have to be carefully taken into account in the civil protection activities. The first one deals with the "cause and effect" of communication, stating that "some kinds of communication, on some kinds of issues, brought to the attention of some kinds of people, under some kinds of conditions, have some kinds of effects" (Berelson 1948). The second one was expressed by Wilbur Schramm in 1954: "It is misleading to think of the communication process as starting somewhere and ending somewhere. It is really endless. We are little switchboard centres handling and rerouting the great endless current of information ..." (Schramm 1954).

These two statements clearly demonstrate how impossible is to establish a direct and unique link between the original message and the effects on the audience's mind due to the complex process leading to those effects. It is of paramount importance to account for this complexity in the communication of civil protection issues, if definite effects are expected or wanted.

Concerning the judiciary, the question is multifaceted, also depending on the legal framework of each country. In general, the magistrates' action is strictly related to the roles and specific responsibilities of the various actors in risk management. After the 2009 L'Aquila earthquake and the following legal 
controversies (original documents, along with comments, can be found in the following blogs: http://processoaquila.wordpress.com/, http:// terremotiegrandirischi.com/ and http://eagris2014.com/), a lively discussion has been opened worldwide on this theme, that has been addressed in international conferences and workshops (e.g., AGU Fall Meeting 2012; Gasparini 2013, in the Goldschmidt Conference; 2nd ECEES - Special Session "Communication of risk and uncertainty to the general public"; workshop "Who evaluates, who decides, who judges", 2011 -http://www.protezionecivile.gov.it/resources/cms/docu ments/locandina_incontro_di_studio.pdf; workshop "Civil protection in the society of risk: procedures, guarantees, responsibilities", 2013 -http://www. cimafoundation.org/convegno-nazionale-2013/), as well as in books and peer reviewed papers (e.g., DPC and CIMA Ed. 2013, 2014; Alexander 2014a, b; Gabrielli and Di Bucci 2014; Mucciarelli 2014). Due to the importance at international level of this issue, the Global Science Forum of the Organisation for Economic Co-operation and Development (OECD) promoted an activity, involving senior science policy officials of the OECD member countries in a study of "the quality of scientific policy advice for governments and consequences on the role and responsibility of scientists" (http://www.oecd.org/sti/sci-tech/ oecdglobalscienceforum.htm).

The experience currently made in Italy, referred to many different kinds of risks, can be summarized by quoting the words of the Head of the Italian Department of Civil Protection: “. . . a significant increase of the judiciary actions after a disaster has occurred, to find the guilt in the behaviour of the catastrophe management actors. The investigation area is enlarged to the phase of prevision and of "prevision information management' ..." (Gabrielli 2013).

In this perspective, it can be easily understood that decisions of the judiciary can significantly affect the behaviour of the civil protection individual stakeholders and then of the system, as pointed out in the proceedings of one of the workshops mentioned above (DPC and CIMA 2013). Some passages in these proceedings provide the opinion of some judges and experts of criminal law on the bias that can affect the legal interpretation and the possible consequences of a punishing approach (i.e., an approach which looks only for a guilty party after a catastrophic event) on the decision-making process. For instance, Renato Bricchetti, president of the Court of Lecco, states: "I realize ... that most of the people feel the need to find a responsible, I don't want to say a scapegoat, but to know who has to be blamed for what happened. And the mass media world amplifies this demand for justice". Moreover, Francesco D'Alessandro, Professor of Criminal Law at the Università Cattolica of Milan, addresses the "Accusatory approach to the error: a scheme of analysis for which, in case of errors or incidents, the main effort is made to find who is the possible responsible for the event that occurred, in order to punish him. Whereas those elements of the organization that may have contributed to the adoption of a behaviour characterized by negligence, imprudence, incompetence, are left in the background." He also affirms that: "As a consequence, even if you punish a specific person, the risk conditions and the possibility to commit the same error again still continue to persist." Finally, D'Alessandro depicts the devastating 
effects of this approach on the risk mitigation: "The accusatory approach ... induces a feeling of fear in the operators of the possible punishment ... and this keeps them from reporting on the near misses, thus impeding learning by the organization. This phenomenon ... is characterized by a progressive, regular adoption of behaviours that are not aimed at better managing the risk, but rather at attempting to minimize the possibility to be personally involved in a future legal controversy."

Dealing with the role played by citizens in a fully developed civil protection system, it has to be underlined that this role is fundamental both in ordinary and in emergency conditions.

On the one hand, in ordinary conditions, citizens should reduce as much as they can the risks threatening their lives and property, by:

- asking for and/or contributing to create adequately safe conditions at their places of work, study, and entertainment;

- verifying that civil protection authorities have prepared in advance the preventive measures that must be adopted in case of catastrophic events, especially civil protection plans, of which citizens are primary users;

- being more aware of the risks which they are exposed to, and having an adequate civil protection culture, which would allow them to adopt the aforementioned precautionary measures and induce political representatives to carry out riskprevention policies through both their vote and their active involvement in the local political activities.

On the other hand, in case (or in the imminence, when possible) of an event, citizens can undertake different actions, depending on the kind of risk and on the related forecasting probabilities:

- in the immediate aftermath of an event (or in case of an alert), they should follow and implement the civil protection plans (if available) and the correct behaviours learned;

- in case of very low occurrence probabilities, they should adopt individual behaviours, more or less cautious, calibrated on their own estimate of the risk acceptability.

Finally, citizens can provide support to the civil protection system also by being part of volunteers organizations.

\subsection{Civil Protection and Science}

Two main aspects of the relationships between civil protection and science are relevant from the civil protection point of view:

- scientific advances can allow for more effective civil protection decisions and actions concerning the entire risk cycle; 
- civil protection has to suitably re-shape its activities and operational procedures to include the scientific advances, as soon as they become available and robust.

In order to fully understand the problems and the possible solutions in the civil protection - science relationships, it is essential to explain what "having procedures" means for a civil protection system, and to provide an overview of the possible scientific products for civil protection use and of the organization of the Italian civil protection system.

\subsubsection{Civil Protection Procedures}

Civil protection operates following pre-defined procedures, which are needed on the one hand to improve its efficiency in decision-making and to rapidly undertake actions during a crisis or an emergency and, on the other hand, to make roles and responsibilities clear. As the procedures are defined quite rigidly and involve many actors, modifying them is often "uncomfortable", especially on the basis of those new scientific advancements that increase the uncertainties or do not quantify them.

The progressive updating of the procedures is made even more complex by the fact that civil protection organizations are different in different countries. A technical-scientific product/tool/study that is suitable for one country or for a given civil protection system can therefore turn out to be inadequate for another one. As a matter of fact, each civil protection organization has its own procedures, that are derived from the distillation of practical experiences and successive adjustments. These procedures are somehow "digested" by the civil protection personnel and officials, by the civil protection system and, sometimes, by media and population, thus creating complex interrelationships which are hard and sometimes dangerous to change abruptly.

Changing procedures is an inescapable fact, that however can be much more difficult and slow than making scientific advances and improving scientific tools.

\subsubsection{Scientific Products for Civil Protection}

Scientific products, i.e., any scientific result, tool or finding, for their intrinsic nature do not usually derive from an overall view of the reality, but they tend to emphasize some aspects, while neglecting or oversimplifying some others. Therefore, often research findings can turn out to be unreliable for practical applications, and sometimes falsely precise or tackling only part of a problem, whereas they leave unsolved other important parts. To minimize this contingency, research activities finalized to civil protection aims should proceed in close cooperation with civil protection stakeholders in defining objectives and products to achieve, as well as in validating results and/or tools. 
Generally speaking, science can, more or less effectively, contribute to civil protection in the following two ways:

1. with specific scientific products, explicitly requested (and generally funded) by civil protection and subjected to a wide consensus of the scientific community; the scientific results provided, although responding to the civil protection needs, can be still not suitably shaped for a direct or immediate translation into civil protection procedures and actions, needing further adaptation and a pre-operational stage before their full operational utilization.

2. with scientific products made freely available by the scientific community, which typically pertain to one of the following three categories:

(i) many different findings on the same subject; as expected in these cases, in which the scientific community is still developing a theme and conclusive result is still far from being reached, they can be (and often are) inconsistent or conflicting among them;

(ii) totally new products "standing out from the crowd"; they are proposed by the authors as innovative/revolutionary/fundamental, and are often conveyed to the public through media, claiming their great usefulness for risk mitigation. In this way, these products can benefit from the favour of a large public that, however, has not the needed expertise to evaluate the quality of their scientific content;

(iii) totally new and often scientifically valuable products; in any case they need to be adapted, if actually possible, to civil protection operability.

A more in-depth and articulated analysis of the different scientific products proposed for civil protection use is shown in section 4 .

\subsubsection{The Italian National Civil Protection System}

In Italy, civil protection is not just a single self-contained organization but a system, called National Service of Civil Protection (SNPC), which operates following the idea that the civil protection is not an administration or an authority, but rather a function that involves the entire society. Several individuals and organizations contribute with their own activities and competences to attain the general risk mitigation objectives of SNPC.

The coordination of this complex system is entrusted to the National Department of Civil Protection, which acts on behalf of the Prime Minister. The SNPC's mandate is the safeguarding of human life and health, property, national heritage, human settlements and environment from all natural or manmade disasters.

All the ministries, with their national operational structures, including Fire Brigades, Police, Army, Navy, Air Force, Carabinieri, State Forest Corps and Financial Police, as well as Prefectures, Regional and local civil protection organizations, contribute to SNPC actions. Public and private companies of highways, 
roads and railways, electricity and telecommunication, as well as volunteers associations and individual citizens, are part of the system. The volunteers associations can have both general aims of assistance to the population, and specific aims related to particular technical/professional skills (for instance, architects, engineers, geologists, medical doctors, etc.). Finally, an important strength of SNPC is represented by the full involvement of the scientific community, which enables timely translation of up-to-date scientific knowledge into operability and decision making.

All the kinds of natural and manmade risks are dealt with by the SNPC, including seismic, hydrogeological, flood, volcanic, forest fire, industrial and nuclear, technological, transports, supply networks and environmental risks. Different kinds of engagement are envisaged, at different territorial levels, according to the local, regional or national level of the emergency to be faced and, more in general, to the civil protection activities to be carried out in ordinary conditions.

\subsection{How Science Contributes to Civil Protection}

Science can provide different kinds of contributions to civil protection. They can be distinguished and classified according to the type of relationship between the scientific contributors and the civil protection organizations. The main kinds of contributions can be categorized as follows:

(i) well-structured scientific activities, permanently performed by scientific institutions on behalf of civil protection organizations, which usually endow them;

(ii) finalized research activities carried out by scientific institutions, funded by civil protection organizations to provide results and products for general or specific purposes of civil protection;

(iii) advices regularly provided by permanent commissions or permanent consultants of civil protection organizations;

(iv) advices on specific topics, provided by temporary commissions ad hoc established by civil protection organizations;

(v) research activities developed in other frameworks and funded by other subjects (European projects, Regional funds, etc.), that achieve results of interest for civil protection organizations, especially when these latter are involved as end-users;

(vi) free-standing research works, producing results of potential interest for civil protection without any involvement of civil protection organizations.

Hereinafter, the above different kinds of scientific contributions are described and discussed in the light of the experience made by the DPC, devoting a special concern to the criticalities observed. 


\subsubsection{Permanent (i) and Finalized Research Activities (ii) for Civil Protection - The Competence Centres}

In Italy, there is a long-lasting tradition of interactions between civil protection and scientific community on earthquake research topics. A first important link was developed after the 1976 Friuli earthquake and continued until 2002, with projects funded by the DPC and coordinated by the National Research Council that gave a strong impulse to this research field, involving the whole scientific community. An even stronger integration between civil protection and research was then promoted in 2004, with a new organization of the relationships between the DPC and the scientific community, on behalf of which the "Competence Centres" play a primary role.

The Competence Centres (CC) of the DPC are scientific institutions which provide services, information, data, elaborations, technical and scientific contributions for specific topics, to share the best practices in risk assessment and management. These centres are singled out by a decree of the Head of DPC. The activities carried out by the CC are funded by DPC through annual agreements, according to general multi-year understandings that establish the main lines of activities to be carried out in the reference period.

The interrelationships between DPC and CC are in many cases multifaceted, and their management needs therefore a unified view. With this aim, for each $\mathrm{CC}$ which deals with the seismic risk a DPC-CC joint committee has been established. This committee, made of an equal number of DPC and CC components (typically 3-4 representatives per part), manages practically the relationships between the DPC and the CC. Ultimately, the job of the joint committee, consists of acting as a sort of hinge, a functional linkage between the two worlds of civil protection and seismic risk science. This role, as much interesting as uncomfortable, guarantees consistency in the management of all the activities concerned. In addition to the committee components, DPC representatives assure the correct finalization for civil protection application of each activity/project developed by a $\mathrm{CC}$ and of the final products, directly interacting with the $\mathrm{CC}$ scientific managers of the activity/ project. DPC representatives in charge and CC scientific managers report to their directors and to the DPC-CC joint committee on the regular development of the activities, on the possible needs that could arise and on the relevant decisions to be taken, according to the scheme shown in Fig. 2.2.

The three main $\mathrm{CC}$ for the seismic risk are:

- INGV - the National Institute of Geophysics and Volcanology;

- ReLUIS - the National Network of University Laboratories of Earthquake Engineering;

- EUCENTRE - the European Centre for Training and Research in Earthquake Engineering.

INGV provides DPC with scientific advices and products related to seismological (as well as volcanological, not addressed in the present work) issues, while 


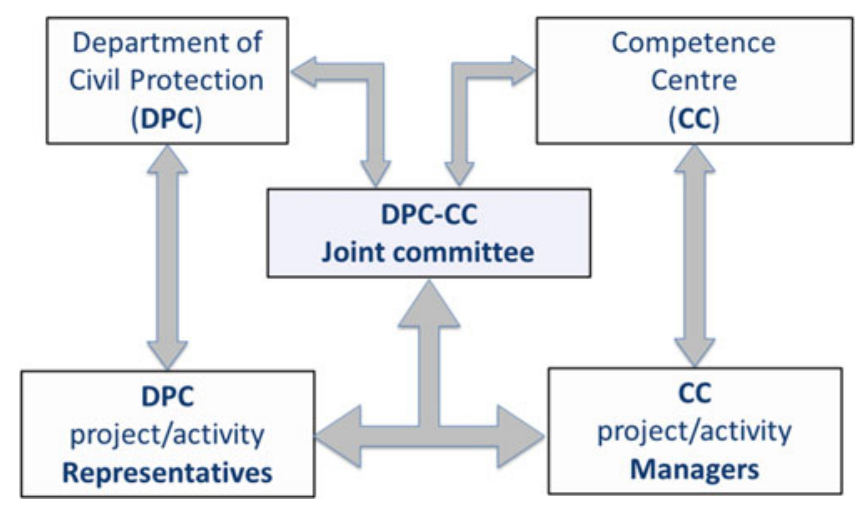

Fig. 2.2 Scheme of the relationships management between the Italian Department of Civil Protection and a Competence Centre

EUCENTRE and ReLUIS operate in the field of earthquake engineering. All of them represent the reference scientific system on seismic risk for DPC, and provides the most advanced scientific knowledge in Seismology and Earthquake Engineering. Moreover, these $\mathrm{CC}$ have the capability to produce considerable progress and organisation of the scientific information and to promote a strong finalisation of research towards products for civil protection purposes (Dolce 2008).

\subsubsection{INGV}

A 10 year agreement between DPC and INGV (http://www.ingv.it/en/) was signed in 2012, for the period 2012-2021. It envisages three types of activities, that are described hereinafter with regards to earthquakes.

A-type: operational service activities.

Several different activities pertain to this type:

- seismic monitoring and 24/7 surveillance, through the National Earthquake Centre (INGV-CNT),

- implementation and maintenance of data bases useful for civil protection purposes,

- preparedness and management of technical-scientific activities during the emergencies,

- divulgation and training activities in coordination with DPC.

B-type: development of operational service activities.

On the one hand, this type concerns the actions to be undertaken by DPC and INGV in order to improve and develop the activities mentioned in the above A-type description. On the other hand, it deals with the pre-operational, and 
then operational, implementation of research achievements (C-type below) for civil protection. This occurs when validated scientific outcomes derived from C-type activities, or from other INGV research, have to be transformed into products that can be submitted to civil protection pre-operational, experimental testing. In case of positive outcome, the scientific product/tool/study can then become part of a fully operational service among the A-type activities.

C-type: finalized research activities.

They consist of seismological-geological projects funded by DPC that involve the entire scientific community.

Some examples of the above three types of activities are described in the following paragraphs.

\section{"A-Type" Activities}

According to a national law (D. Lgs. 381/99), INGV has in charge the seismic (and volcanic) monitoring and surveillance of the Italian territory. It manages and maintains the velocimetric National Seismic Network (more than 300 stations), whose data are collected and elaborated at the INGV-CNT, providing DPC with quasi-real-time information on location and magnitude of Italian earthquakes, with the capability to detect $M>2$ earthquakes all over the Italian territory (Sardinia excluded, in relation to the negligible seismicity of this region) and $\mathrm{M}>1$ in many of the most hazardous regions (see Fig. 2.3).

Among the INGV A-type activities, the implementation and maintenance of data bases that are important for their civil protection applications deserve to be mentioned. For instance:

- DISS - The Database of Individual Seismogenic Sources (http://diss.rm.ingv.it/ diss/; Basili et al. 2008; DISS Working Group 2010; Fig. 2.4) is, according to http://diss.rm.ingv.it/diss/UserManual-Intro.html, a "georeferenced repository of tectonic, fault and paleoseismological information; it includes individual, composite and debated seismogenic sources. Individual and composite seismogenic sources are two alternative seismic source models to choose from. They are tested against independent geophysical data to ensure the users about their level of reliability". Each record in the Database is backed by a Commentary, a selection of Pictures and a list of References, as well as fault scarp or fold axis data when available (usually structural features with documented Late Pleistocene - Holocene activity). The Database can be accessed through a web browser or displayed on Google Earth. DISS was adopted as the reference catalogue of Italian seismogenic sources by the EU SHARE Project (see below). 


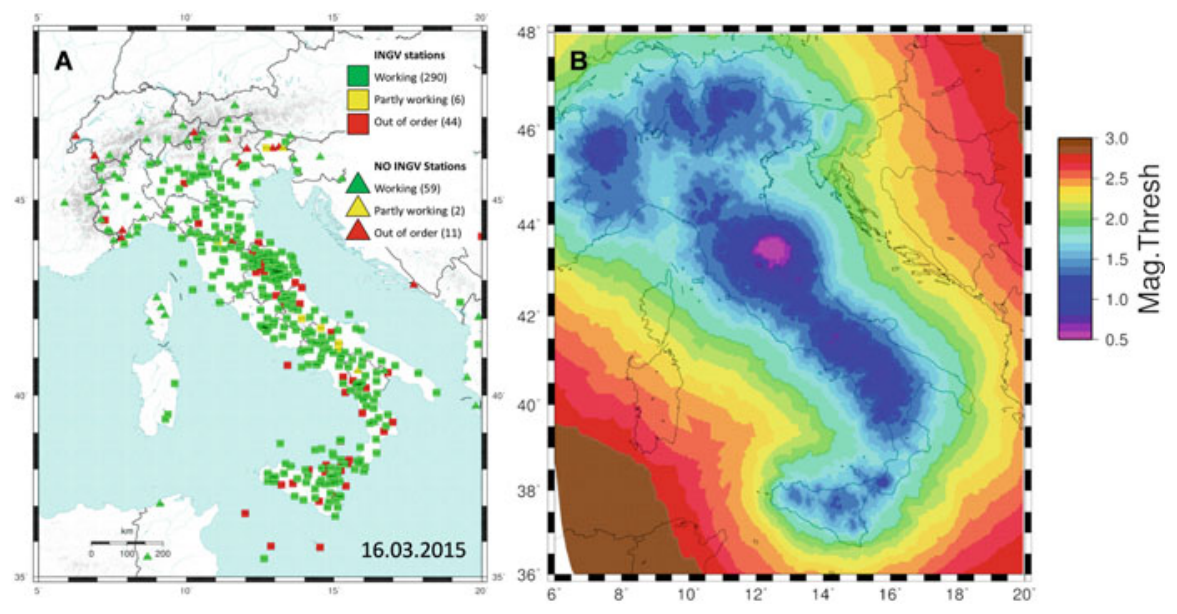

Fig. 2.3 (a) Distribution of the Italian seismic network operated by INGV; and (b) example of magnitude detection threshold on march 16, 2015 (Data provided by INGV to DPC)

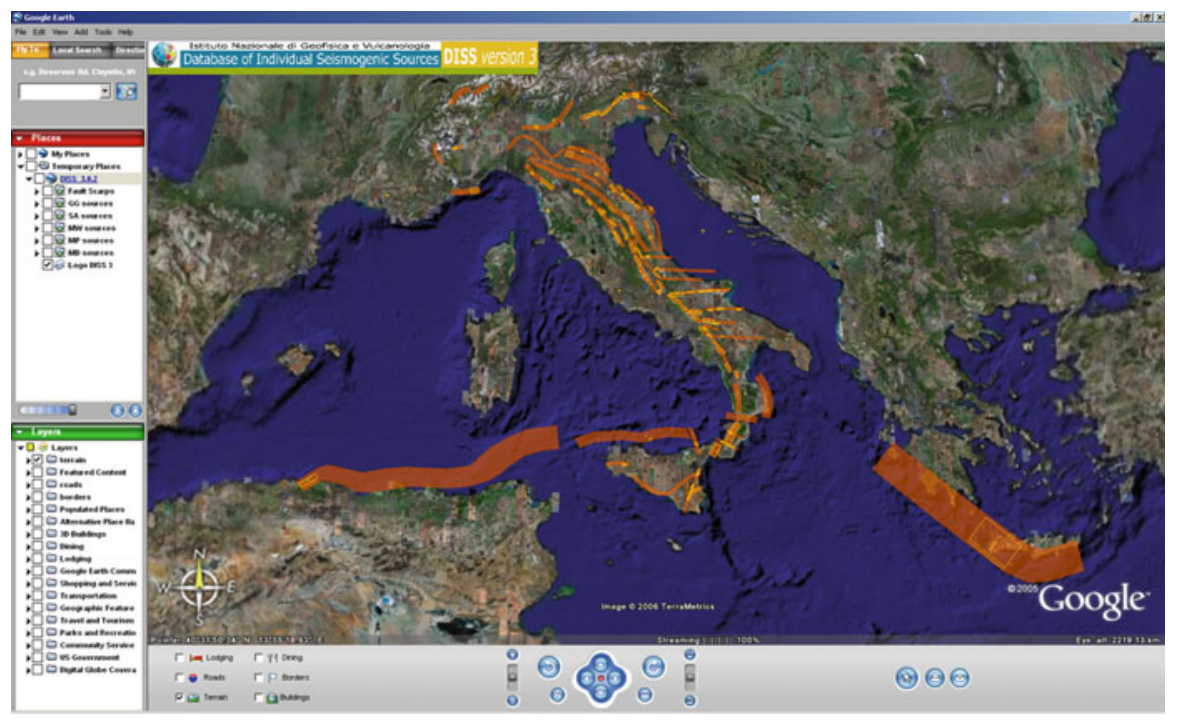

Fig. 2.4 DISS website (http://diss.rm.ingv.it/diss/; Basili et al. 2008; DISS Working Group 2010)

- ISIDe - The Italian Seismological Instrumental and parametric Data-basE (http://iside.rm.ingv.it/iside/standard/index.jsp; Fig. 2.5a) provides verified information on the current seismicity as soon as it is available, once reviewed by the seismologists working at the INGV-CNT, along with the updated information of past instrumental seismicity contained in the Italian Seismic Bulletin (Mele and Riposati 2007). 


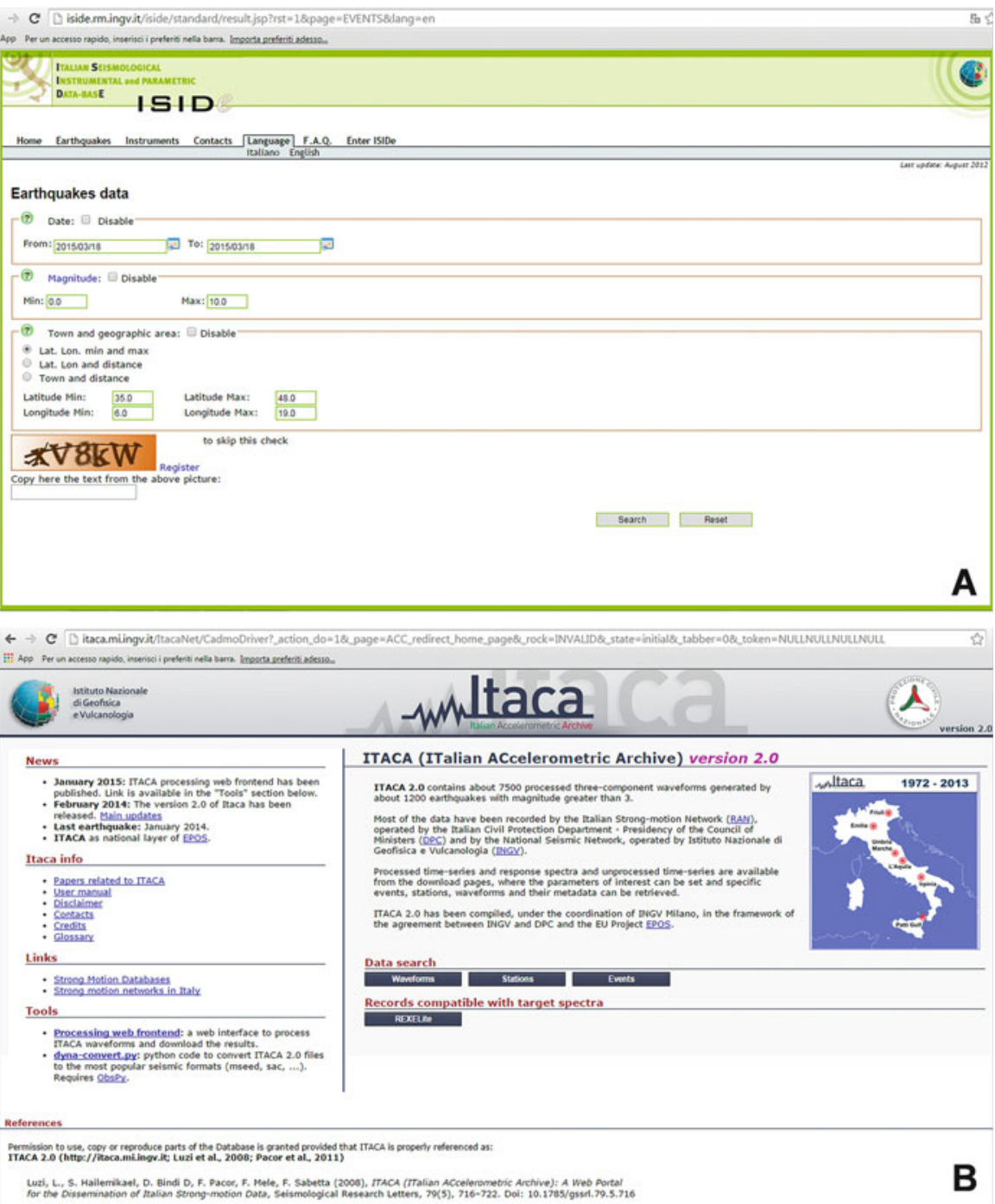

Fig. 2.5 Websites of the data bases (a) ISIDE, and (b) ITACA

- ITACA - The ITalian ACcelerometric Archive (http://itaca.mi.ingv.it; Fig. 2.5b) contains about 7,500 processed three-component waveforms, generated by about 1,200 earthquakes with magnitude greater than 3 . Most of the data have been recorded by the Italian Strong-motion Network (http://www.protezionecivile. gov.it/jcms/it/ran.wp), operated by DPC, and also by the National Seismic Network, operated by INGV (http://itaca.mi.ingv.it/; Luzi et al. 2008; Pacor et al. 2011). Processed time-series and response spectra, as well as unprocessed 


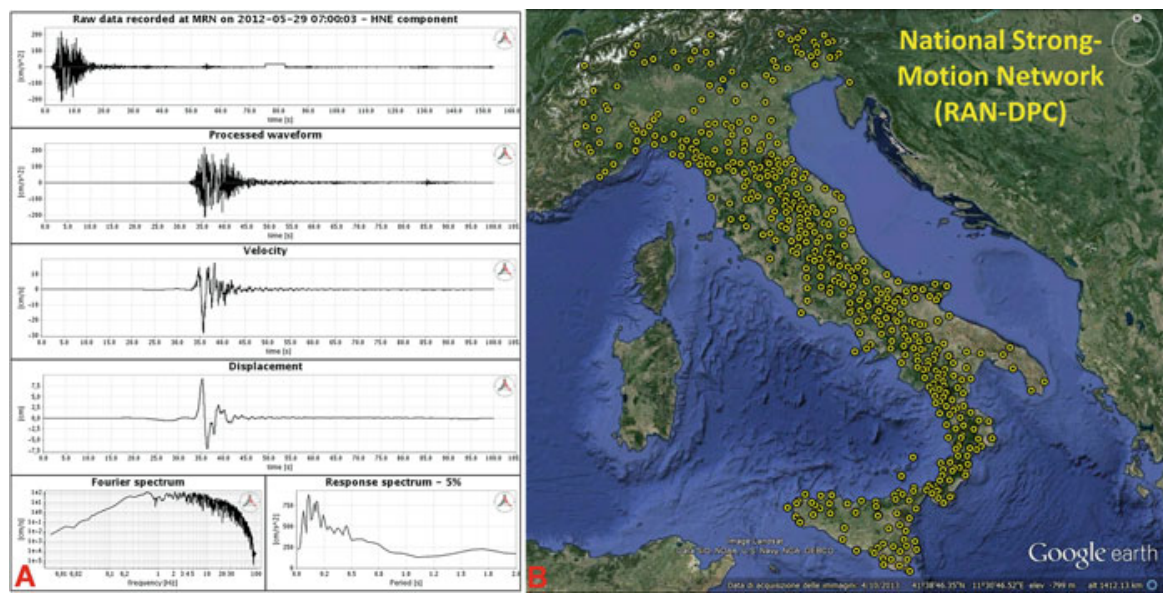

Fig. 2.6 (a) waveforms extracted from ITACA database, and (b) geographical distribution of the National Strong-Motion Network (RAN-DPC)

time-series, are available from the download pages, where the parameters of interest can be set and specific events, stations, waveforms and related metadata can be retrieved (Fig. 2.6).

\section{"B-Type" Activities}

Apart from the actions aimed at improving and developing the operational service activities (A-type), among the pre-operational and operational implementation of research achievements for civil protection, there are some activities recently implemented that deserve to be mentioned.

\section{CPS - Centre of Seismic Hazard}

The Centre of Seismic Hazard (INGV-CPS) was established in 2013 (http:// ingvcps.wordpress.com/chi-siamo/), promoted and co-funded by DPC. It operates, in the current experimental phase, working on three different time scales of seismic hazard: long-term, mid-term and short-term, for different possible applications.

For the long-term seismic hazard the time-window is typically of 50 years, assuming the basic hypothesis of time-independence for the earthquake occurrence. Within this framework, the CPS aims at updating the seismic hazard model of Italy and the relevant maps according to the most recent advances in the international state-of-the-art and using the most updated information that contributes to the hazard assessment of the Italian territory.

For the mid-term seismic hazard the time-window is typically of years to tens of years, assuming some time-dependence hypothesis to model the earthquake 
occurrence. In this case, the activities are aimed at producing and comparing timedependent hazard models and maps, and defining a consensus-model or an ensemble-model that can be useful to set up risk mitigation strategies for the near future.

For the short-term seismic hazard (also known in the international literature as Operational Earthquake Forecasting, OEF), that is modelled using time-dependent processes, the time-window is typically days to months. About its possible outcomes, Jordan et al. (2014) explain: "We cannot yet predict large earthquakes in the short term with much reliability and skill, but the strong clustering exhibited in seismic sequences tells us that earthquake probabilities are not constant in time; ... OEF must provide a complete description of the seismic hazard-ground-motion exceedance probabilities as well as short-term rupture probabilities-in concert with the long-term forecasts of probabilistic seismic-hazard analysis (PSHA)".

The CPS activities are carried out by a dedicated working group, which uses a new technological infrastructure for (i) the computation of the seismic hazard, by integrating the most recent data and different models, (ii) the management of the available data bases, and (iii) the representation of the hazard estimation, even using web applications. Moreover, IT tools are developed to facilitate the preparation, implementation and comparison of hazard models, according to standard formats and common procedures, in order to make fast checks of the sensitivity of the estimations. Synergies with some international activities, like the Collaboratory for the Study of Earthquake Predictability, CSEP (http://www.cseptesting.org/), and the Global Earthquake Model, GEM (http://www.globalquakemodel.org/), as well as with the Italian seismic hazard community, are pursued.

\section{CAT - Tsunami Alert Centre}

The Tsunami Alert Centre (INGV-CAT) was established in 2013 in order to contribute to the Italian Tsunami Alert System (see Fig. 2.7). A Memorandum of Understanding was then signed on January 16th, 2014, between DPC and INGV.

This centre operates within the activities promoted by the Intergovernmental Coordination Group for the Tsunami Early Warning and Mitigation System in the North-Eastern Atlantic, the Mediterranean and connected seas (ICG/NEAMTWS). This group was formally established by the Intergovernmental Oceanographic Commission of UNESCO (IOC-UNESCO) through the Resolution IOC-XXIII-14.

The Italian Tsunami Alert System deals with earthquake-induced tsunamis and encompasses different functions: the event detection; the alert transmission to the potentially involved areas and, more in general, to the entire civil protection system; the preparedness to the operational response by drawing up the tsunami civil protection plans at different scales; the citizens' formation about the correct behaviour in the case of event. These functions are carried out by different subjects which operate in close coordination. In particular, three public administrations are involved in this task: DPC, INGV and ISPRA (Italian Institute for Environmental Protection and Research) with the following roles: 


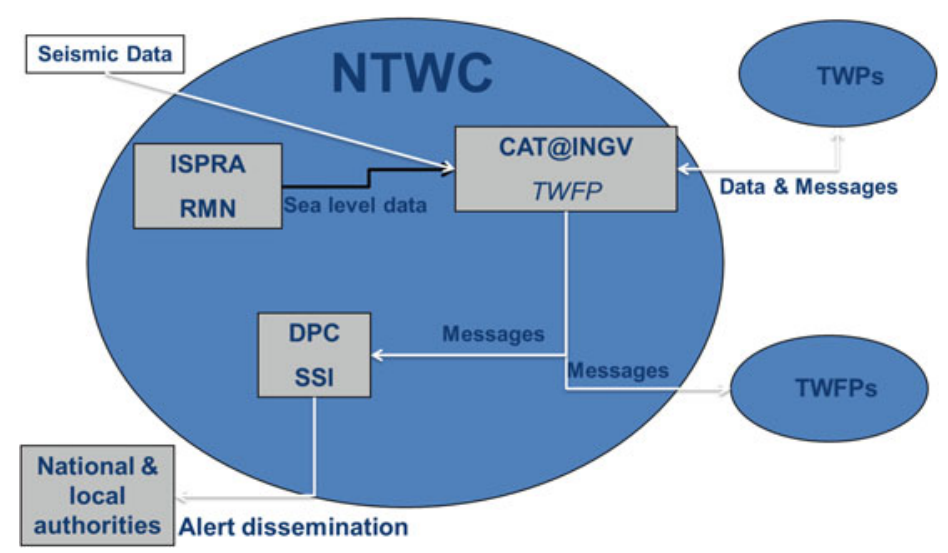

Fig. 2.7 The Italian Tsunami Warning System (Michelini A, personal communication 2014)

- DPC has the role of Tsunami National Contact (TNC);

- INGV has the role of National Tsunami Warning Centre (NTWC); at national scale, this corresponds to the INGV-CAT, which is part of the INGV-CNT;

- the Director of the INGV-CNT has the role of National Tsunami Warning Focal Point (NTWFP);

- ISPRA guarantees the sea level monitoring and surveillance, ensuring the transmission to the INGV-CAT of the data acquired by its National Mareographic Network (RMN). From August 2013, ISPRA sends to CAT@INGV sea level measurements recorded in real time.

Since October 1st, 2014, the INGV-CAT has assumed the role of Candidate Tsunami Watch Provider (CTWP) for the IOC/UNESCO member states in the Mediterranean. Moreover, a DPC officer is currently in charge of the IGC/NEAMTWS Vice-Chair.

The INGV-CAT will operate within the INGV earthquake operational room, also with the mission to organize the scientific and technological competences which deal, for instance, with the physics and the modelling of the seismogenic and tsunami sources, the tsunami hazard, the real-time seismology, the related computer-science applications. The strong connection with the INGV earthquake operational room will allow the INGV-CAT to take advantage from the INGV experience on seismic monitoring activities.

At present, the entire Italian Tsunami Alert System is undergoing a pre-operational testing phase, which involves the operational structures of the National Service of Civil Protection and representatives of the Regional authorities. 


\section{"C-Type" Activities}

DPC promotes a series of seismological projects that are organized in a research program developed to achieve objectives of specific interest for civil protection in the field of earthquakes. They are funded by DPC and managed by INGV in the frame of a 10 year agreement between DPC and INGV (2012-2021; http://istituto. ingv.it/l-ingv/progetti/progetti-finanziati-dal-dipartimento-di-protezione-civile-1/ Progetti\%20DPC-INGV\%20Convenzione\%20C). These projects also involve many universities and other research institutes, and in general are carried out with the contribution of the national and international scientific community.

The ongoing research program is organized in three main projects, which are presently coming to an end.

- Project S1 - Base-knowledge improvement for assessing the seismogenic potential of Italy.

This project is structured into three parts. Two of them address the activities related to geographical areas of interest (Po Plain, Sannio-Matese to the Calabria-Lucania border), whereas the third one concerns the activities which may have a specific interest as special case studies or application of innovative techniques. The project has been structured in sub-projects and tasks. All sub-projects address regional-scale issues and specific targets within a region, with one exception, aimed at promoting the optimization of techniques which are used for earthquake geology and seismic monitoring.

- Project S2 - Constraining observations into seismic hazard

This project aims at comparing and ranking different hazard models, according to open-shared and widely agreed validation rules, in order to select the best "local" hazard assessment. The goal is to validate the hazard maps on instrumental observations, combining expected shakings at bedrock with sitespecific information gathered at local scale.

- Project S3 - Short term earthquake forecasting

The basic aim of this project is the full exploitation of the huge amount of data collected, with special care to the potential detection of possible large scale/short term (weeks to months) transient strain field variations, that could be related to incoming earthquakes. Two are the study areas of major concern (Po plain and Southern Apennines). In particular, due the larger amount of information available for the Po Plain (GPS, InSAR, piezometric data, etc.) most of activities is focused on this area.

The total funding for the current, 2 years seismological topics was $2 \mathrm{M} €, 60 \%$ of which have been devoted to the participation of universities and other scientific institutions, while $40 \%$ are for the research units of INGV. Several tens of research units are involved in this program. 


\subsubsection{ReLUIS}

DPC and ReLUIS (http://www.reluis.it/) signed a 5 years agreement for the 2014-2018 period. The object of the agreement is related to two main groups of activities carried out for DPC in the field of earthquake engineering, namely the technical-scientific support and divulgation, and the development of knowledge. More in detail, ReLUIS supports DPC in:

- post-earthquake technical emergency management;

- training and divulgation activities in earthquake engineering and seismic risk (teachers' availability, high-level course organization, meetings and seminars, technical-scientific divulgation, conferences);

- training of professionals on the post-earthquake evaluations;

- campaigns of divulgation and spreading of the civil protection culture.

For what concerns the development of knowledge, themes of civil protection interest are developed according to the following lines of activity:

- finalized research programs on earthquake engineering and seismic risk mitigation;

- coordination with the DPC, CC and with other technical-scientific subjects;

- implementation, revision and publication of manuals, guidelines, pre-normative documents;

- assistance for drafting/revising technical norms.

The finalized research programs are in a continuity line with the previous projects, that started in 2005 (Manfredi and Dolce 2009). For the 2014-2016 period, they are organized according to the following general lines:

(i) General Themes, relevant to design, safety verifications and vulnerability assessment of buildings and constructions (e.g., R/C and masonry buildings, bridges, tanks, geotechnical works, dams, etc.);

(ii) Territorial Themes, aimed at improving the knowledge of the types of buildings and of their actual territorial distribution, in order to set up tools for the improvement of the vulnerability and risk assessment at national/local scale;

(iii) Special Projects on specific topics (e.g. distribution networks and utilities, provisional interventions, etc.) that are not dealt with in the General Themes, or on across-the-board themes (e.g., near-source effects on structures, treatment of uncertainties in the safety assessment of existing buildings).

Territorial Themes deserve a special attention from the civil protection point of view. Seismic risk evaluations at the national scale are currently based on the data derived from the national population census, which includes only some rough data on buildings (age, number of stories, type of structural material, i.e., R/C or masonry). A new approach has been set up, aimed at improving such evaluation for what concerns the vulnerability and exposure components on a territorial basis, trying to extract as much information as possible from the knowledge of local 
experts (i.e., professionals and local administration officials) on the building characteristics. This approach takes profit of the network organization of ReLUIS, that involves more than 40 universities all over Italy. It is based on the identification of the common structural and non-structural features of buildings pertaining to each district of a given municipality, characterized by a good homogeneity in terms of age and main characteristics of the building stock (Zuccaro et al. 2014).

\subsubsection{EUCENTRE}

DPC and EUCENTRE (http://www.eucentre.it/) signed an agreement for the 2014-2016 period. Also in this case, as for ReLUIS, the object of the agreement is related to the two main groups of earthquake engineering activities carried out for DPC, i.e., the technical-scientific support and divulgation, and the development of knowledge. In detail, EUCENTRE supports DPC in:

- training and divulgation;

- experimental laboratory testing on structural models, sub-assemblages and elements;

- management of seismic data banks;

- planning, preparing and managing technical-scientific activities in emergency.

Of particular interest is the management of seismic data banks, due to the implemented capability of making risk and scenario evaluations. This management is organized in the following lines of activities (see Fig. 2.8):

- Tool for System Integration (S.3.0 in Fig. 2.8)

- Seismic risk of the Italian dwelling buildings

- Seismic risk of the Italian schools (S.3.2 in Fig. 2.8)

- Management system of the post-event dwelling needs

- Seismic Risk of the Italian road system

- Seismic Risk of the Italian sea harbours (S.3.5 in Fig. 2.8)

- Seismic Risk of the Italian earth dams (S.3.6 in Fig. 2.8)

- Seismic Risk of the Italian airports

- Data base of past earthquake damage to buildings

- Seismic vulnerability of the Italian tunnels

- WebGIS for private buildings upgrade funded by the State with Law n. 77/2009, Art. 11

The activities devoted to the development of knowledge are related to the two following themes: (1) Maps of seismic design actions at uniform risk, and (2) Fragility curves and probability of damage state attainment of buildings designed according to national codes. This latter theme encompasses the seismic safety of masonry buildings (including the limited knowledge of the structure and of the uncertainty sources, the improvement of procedures of analysis and verification of structures, and the fragility curves of masonry buildings), the Displacement Based 


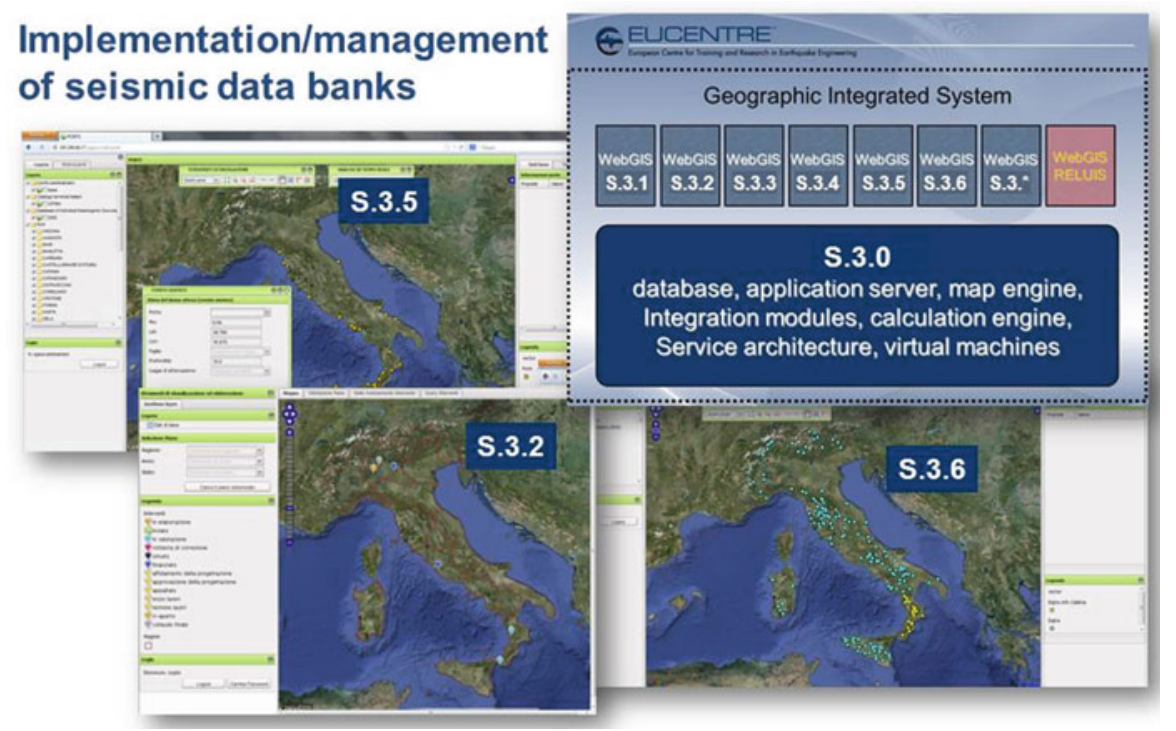

Fig. 2.8 Examples of WEB-GIS applications by EUCENTRE

Design in low hazard zones and relevant software implementation DBDsoft, and the Fragility curves of precast building structures.

\subsubsection{Permanent Commissions - The Major Risks Commission}

The National Commission for forecasting and prevention of Major Risks is the highest-level, connecting structure between the Italian civil protection system and the scientific community. It is an independent scientific consultation body of DPC, but it is not part of the Department itself. The Commission was established by Law n. 225/1992. Its organization and functions have been re-defined on 2011 (DPCM 7 October 2011).

The Major Risks Commission provides advice on technical-scientific matters, both autonomously and on request of the Head of the Department of Civil Protection, and may provide recommendations on how to improve capabilities for evaluation, forecasting and prevention of the various risks.

The Commission is structured in a Presidency Office and five sectors relevant to:

- seismic risk,

- volcanic risk,

- weather-hydrogeological, hydraulic and landslide risk, 
- chemical, nuclear and industrial and transport risk,

- environmental and fire risk.

Each sector has a coordinator and ten to twelve members coming from the whole scientific community, including experts from the CC.

The term of the office is 5 years. The Commission meets separately for each risk sector, or in joint sessions for the analysis of inter-disciplinary matters. It usually meets once a year in plenary session and normally gathers in the DPC premises. In order to get further scientific contributions, the President can invite also external experts without voting right.

As far as the formal communications of the Commission are concerned, according to the current rules the results of each meeting have to be summarized in minutes that are released to the Head of the Department of Civil Protection. In case of specific communication needs, the same results can be further summarized in a public statement, which represents the only official way to provide the opinions of the Commission to the public.

\subsubsection{Commissions on Specific Subjects}

In the recent past, DPC turned to the advice of high-level international panels of scientists to deal with specific and delicate questions of civil protection interest. Two cases related to seismic risk are summarized in this section.

\subsubsection{ICEF - International Commission on Earthquake Forecasting}

The International Commission on Earthquake Forecasting was charged by DPC on May 20th, 2009, after the April 6th, 2009, L'Aquila earthquake, to report on the current state of knowledge of short-term prediction and forecasting of tectonic earthquakes and to indicate guidelines for utilization of possible forerunners of large earthquakes to drive civil protection actions. The Commission worked during 4 months to firstly draft an Executive Summary, that was released on October 2nd, 2009. The final ICEF Report, including state-of-art, evaluations and findings, was then completed and published on August 2011 (Jordan et al. 2011).

The Commission was composed of ten members from nine countries, namely: T. H. Jordan, Chair - USA, Y.-T. Chen - China, P. Gasparini, Secretary - Italy, R. Madariaga - France, I. Main - United Kingdom, W. Marzocchi - Italy, G. Papadopoulos - Greece, G. Sobolev - Russia, K. Yamaoka - Japan, J. Zschau - Germany.

The final ICEF report is organized into five sections, as follows.

I. Introduction: describes the charge to the Commission, the L'Aquila earthquake context, and the Commission's activities. 
II. Science of Earthquake Forecasting and Prediction: summarizes the state of knowledge in earthquake forecasting and prediction and discusses methods for testing and validating forecasting models.

III. Status of Operational Earthquake Forecasting: reports on how governmental agencies in China, Greece, Italy, Japan, Russia and United States use operational forecasting for earthquake risk management.

IV. Key Findings and Recommendations: states the Commission's key findings and makes specific recommendation on policies and actions that can be taken by DPC to improve earthquake forecasting and its utilization in Italy.

V. Roadmap for Implementation: summarizes the DPC actions needed to implement the main recommendations in Italy.

Among the recommendations, it is worth to mention the following ones:

Recommendation A: DPC should continue to track the scientific evolution of probabilistic earthquake forecasting and deploy the infrastructure and expertise needed to utilize probabilistic information for operational purposes.

Recommendation D: DPC should continue its directed research program on development of time-independent and time-dependent forecasting models with the objective of improving long-term seismic hazard maps that are operationally oriented.

Recommendation G2: Quantitative and transparent protocols should be established for decision-making that include mitigation actions with different impacts that would be implemented if certain thresholds in earthquake probability are exceeded.

Although the activities of the CC, especially of INGV, were already in line with such recommendations, they have been somewhat re-addressed, according to them. In the meanwhile, DPC is rethinking about the delicate management of seismic sequences, in the light of the recent scientific advancements suggested by the ICEF Commission. In fact, managing seismic sequences from a civil protection point of view is a very complex question, due to the variety of situations and to the difficulties in structuring well defined procedures.

Main aspects are:

- the very low probabilities of a strong event during swarms and their communication to authorities and to citizens (and then to media). This information competes with different kinds of predictions made available to the public, as well known since the seventies: "In the 1976 . . I warned that the next 10 years were going to be difficult ones for us, with many 'messy' predictions to deal with as we gradually developed a prediction capability. Certainly this has proved to be the case, with many of the most difficult situations arising from predictions by amateurs or self-proclaimed scientists who nevertheless gained public credibility through the news media" (Allen 1982). Although it is well known that the strengthening of constructions remains by far the more effective way to mitigate seismic risk, there is still a strong request for predictions or any action that can 
alleviate worries and fears of citizens caused by shakes during a seismic sequence;

- the relatively high probabilities of strong aftershocks following a major event, especially for what concerns the management of civil protection activities after a big earthquake, like search and rescue, population assistance, damage assessment, safety countermeasures, etc.

These points have to do with the short-term seismic hazard, and DPC is carefully evaluating the possibility of using the related information, availing of INGV-CPS evaluations. An in-depth analysis is going on among and within different DPC sectors (Technical, Emergency, Communication, Press), also involving the Major Risks Commission for what concerns the accuracy of the evaluation methods and other scientific issues. Some of the questions that are more strictly related to civil protection issues are relevant to the communication to the large public and the media (about: delivering simplified or complete probabilistic information, either regularly or just in case of swarms or major events; evaluating how this kind of communication could encourage private and public owners to undertake the structural strengthening of their buildings, rather than discourage them; communicating risk/loss forecast rather than just hazard; educating public, media and administrators to make good use of short-term hazard information), to the civil protection actions that can be effectively carried out, especially related to the knowledge of the high probabilities of strong aftershocks, and to the tasks and responsibilities of information providers and of civil protection organizations.

\subsubsection{ICHESE - International Commission on Hydrocarbon Exploration and Seismicity in the Emilia Region}

The need for an international commission to deal with 'Hydrocarbon Exploration and Seismicity in the Emilia Region' was expressed by the President of the Emilia Romagna Region after the 2012 Emilia earthquakes. Members of the commission were five scientists, namely Peter Styles, Chair - UK, Paolo Gasparini, Secretary Italy, Ernst Huenges - Germany, Stanislaw Lasocki - Poland, Paolo Scandone Italy, and a representative of the Ministry of Economic Development - Franco Terlizzese.

On February 2014, the Commission released a final report answering the following questions, on the basis of the technical-scientific knowledge available at the moment:

1. Is it possible that the seismic crisis in Emilia has been triggered by the recent research activities at the Rivara site, particularly in the case of invasive research activities, such as deep drilling, fluids injections, etc.?

2. Is it possible that the Emilia seismic crisis has been triggered by activities for the exploitation and utilization of reservoirs carried out in recent times in the close neighbourhood of the seismic sequence of 2012 ? 
While the answer to the first question was trivial, once verified that there had been no field research activities at the Rivara site, the answer to the second question was articulated as follows:

- The study does not indicate that there is evidence which can associate the Emilia 2012 seismic activity to the operation activities in Spilamberto, Recovato, Minerbio and Casaglia fields,

- it cannot be ruled out that the activities carried out in the Mirandola License area have had a triggering effect,

- In any case, the whole Apennine orogen under the Po Plain is seismically active and therefore it is essential that the production activity are accompanied by appropriate actions, which will help to manage the seismic risk associated with these activities.

Apart from the specific findings, the importance of the Commission stands in having addressed the induced/triggered seismicity issue in Italy, a research field still to be thoroughly explored in this country. As it can be easily understood, however, not only is this topic of scientific interest, but it has also an impact on the hydrocarbon E\&P and the gas storage activities, due to the increased awareness of national policy makers, local authorities and population (see, for a review of the current activities on induced/triggered seismicity in Italy, D’Ambrogi et al. 2014).

\subsubsection{Research Funded by Other Subjects}

In the past, international research projects were little finalized to products for civil protection use, and the stakeholders' role, although somehow considered, was not enough emphasized. Looking at the research funding policy currently undertaken by the European Union, a more active role is expected from the stakeholders (e.g., Horizon 2020, Work Programme 2014-15, 14. Secure societies; http://ec.europa.eu/ research/participants/data/ref/h2020/wp/2014_2015/main/h2020-wp1415-security_ en.pdf) and, among them, from civil protection organizations, as partners or end-user advisors. Some good cases of EU-funded research projects, finalised to the achievement of results potentially useful for civil protection can be mentioned, however, also for the previous EU Seventh Framework Program. Three examples are here discussed, to show how important is the continuous interaction between scientific community and civil protection stakeholders to achieve results that can be exploited immediately or prospectively in practical situations, and how long is the road to get a good assimilation of scientific products or results within civil protection procedures.

A different case, not dealt in detail, is represented by the GEM Programme and promoted by the Global Science Forum (OECD). This is a global collaborative effort in which science is applied to develop high-quality resources for transparent assessment of earthquake risk and to facilitate their application for risk management around the globe (http://www.globalquakemodel.org/). DPC supported the establishment of GEM in Pavia and currently funds the programme, representing Italy in the Governing Board. 


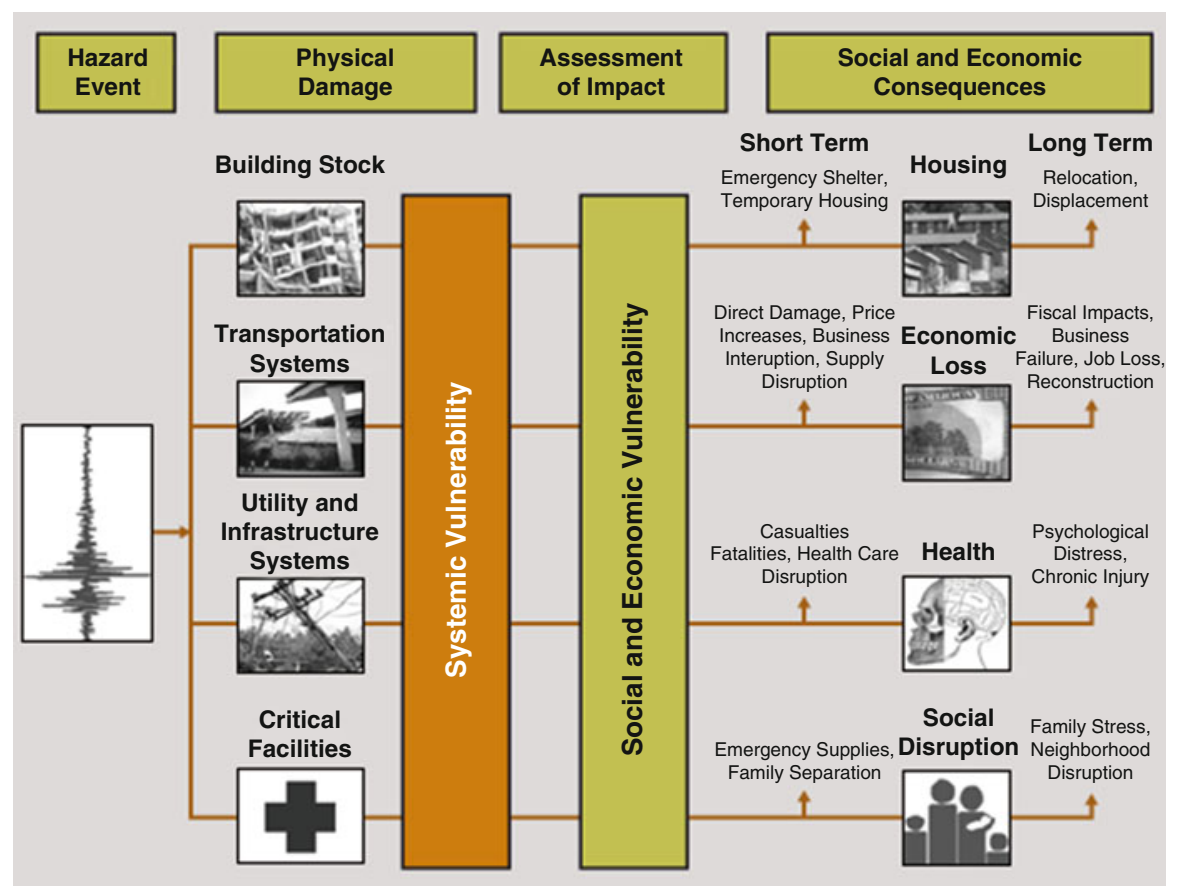

Fig. 2.9 General graphic layout of the concept and goals of SYNER-G (http://www.vce.at/ SYNER-G/files/project/proj-overview.html)

\subsubsection{SYNER-G}

Syner-G is a EU project developed within the Seventh Framework Programme, Theme 6: Environment, and focused on the systemic seismic vulnerability and risk analysis of buildings, lifelines and infrastructures. It started on November 2009, with a 3 years duration (Pitilakis et al. 2014a, b). Eleven partners from eight European countries and three from outside Europe (namely USA, Japan and Turkey) participated to the project, that was coordinated by the Aristotle University of Thessaloniki (Greece) (Fig. 2.9).

The main goals of Syner-G were (see http://www.vce.at/SYNER-G/files/project/ proj-overview.html):

- to elaborate, in the European context, appropriate fragility relationships for the vulnerability analysis and loss estimation of all elements at risk,

- to develop social and economic vulnerability relationships for quantifying the impact of earthquakes,

- to develop a unified methodology and tools for systemic vulnerability assessment, accounting for all components exposed to seismic hazard, considering interdependencies within a system unit and between systems, 
- to validate the methodology and the proposed fragility functions in selected sites (at urban scale) and systems, and to implement them in an appropriate open source and unrestricted access software tool.

DPC acted as an end-user of this project, providing data and expertise; moreover, one of the authors of the present paper was part of the advisory board. The comments made in the end-user final report, summarized below, provide an overview of the possible interactions and criticalities of this kind of projects with civil protection organizations. Among the positive aspects:

- the analysis of the systemic vulnerability and risk is a very complex task;

- considerable steps ahead have been made, in Syner-G, both in questions not dealt with before or in topics that have been better finalized during the project;

- brilliant solutions have been proposed for the problems dealt with and sophisticated models have been utilized;

- of great value is the coordination with other projects, especially with GEM.

It was however emphasized that:

- large gaps still exist between many scientific approaches and practical decisionmakers' actions;

- the use of very sophisticated approaches and models has often required to neglect some important factors affecting the real behaviour of some systems;

- when dealing with a specific civil protection issue, all important affecting factors should be listed, not disregarding any of them, and their influence evaluated, even though roughly;

- a thorough and clear representation of results is critical for a correct understanding by end-users;

- models and results calibration should be referred to events at different scale, due to the considerable differences in the system response and in the actions to be undertaken;

- cases of induced technological risks should be considered as well, since nowadays the presence of dangerous technological situations is widespread in the partner countries.

\subsubsection{REAKT}

REAKT - Strategies and tools for Real time Earthquake risK reducTion (http:// www.reaktproject.eu/) as well is a EU project developed within the Seventh Framework Programme, Theme 6: Environment. It started on September 2011, with a 3 years duration. Twenty-three partners from nine European countries and six from the rest of the world (namely Jamaica, Japan, Taiwan, Trinidad and Tobago, Turkey, USA) participated to the project, that was coordinated by AMRA (Italy; http://www.amracenter.com/en/). Many different types of stakeholders acted as end-users of the Project, among which the Italian DPC, represented 
by the authors of this paper. DPC has actively cooperated, by putting at disposal data and working on application examples.

Among the main objectives of REAKT, one of them deserves specific attention for the scopes of the present paper, namely: "the definition of a detailed methodology to support optimal decision making associated with earthquake early warning systems (EEWS), with operational earthquake forecasting (OEF) and with real-time vulnerability and loss assessment, in order to facilitate the end-users' selection of risk reduction countermeasures".

Much in detail, the attention is here focused on the EEWS and, specifically, on the content of the first version of the "Final Report for Feasibility Study on the Implementation of Hybrid EEW Approaches on Stations of RAN" (Picozzi et al. 2014). Actually, during the project, an in-depth study on the possibility of exploiting for EEW purposes the National Strong-Motion Network RAN was carried out. It is worth to notice that within the project, consistently with the purpose of the related task, the attention was exclusively focused on the most challenging scientific aspects, on which an excellent and exhaustive research work has been carried out. Summarising, the main outcomes of this work are related to the reliability of the real-time magnitude computation and to the evaluation of the lead time, i.e., the time needed for the assessment of the magnitude of the impending earthquake and for the arrival of this information to the site where some mitigating action has to be undertaken before strong shear waves arrive. Such evaluation is referred to the performances and the geographical distribution of the RAN network (see Fig. 2.6b), and to the performances of the algorithm PRESTo (Satriano et al. 2010) for the fast evaluation of the earthquake parameters. The knowledge of the lead time allows an evaluation of the so-called blind and safe zones to be made, where the "blind zone" is the area around the epicentre where the information arrives after the strong shake starts, while the "safe zone" is the surrounding area where the information arrives before and where the shake is still strong enough for the real-time mitigating action to be really useful.

However, neither other technological and scientific requirements that must be fulfilled have been analysed, nor other components necessary to make a complete EEW system useful to mitigate risk have been considered, many of which dealing with civil protection actions. This case appears useful, therefore, to show the different points of view of science and civil protection and to emphasize again how important is to consider all the main factors affecting a given problem - in this case the feasibility and effectiveness of an EEWS - and to evaluate, even roughly, their influence. At this aim, some of the comments made by DPC to the first draft of the final report (Picozzi et al. 2014) are summarized below. The main aspects dealt with are about the effectiveness of EEW systems for real-time risk mitigation. This latter requires at least that:

- efficiency of all the scientific components is guaranteed,

- efficiency of all the technological components is guaranteed,

- targets and mitigation actions to be carried out are defined,

- time needed for the actions is added to the (scientific) lead time, 


\section{Scientific vs. Operational Safe Zone}

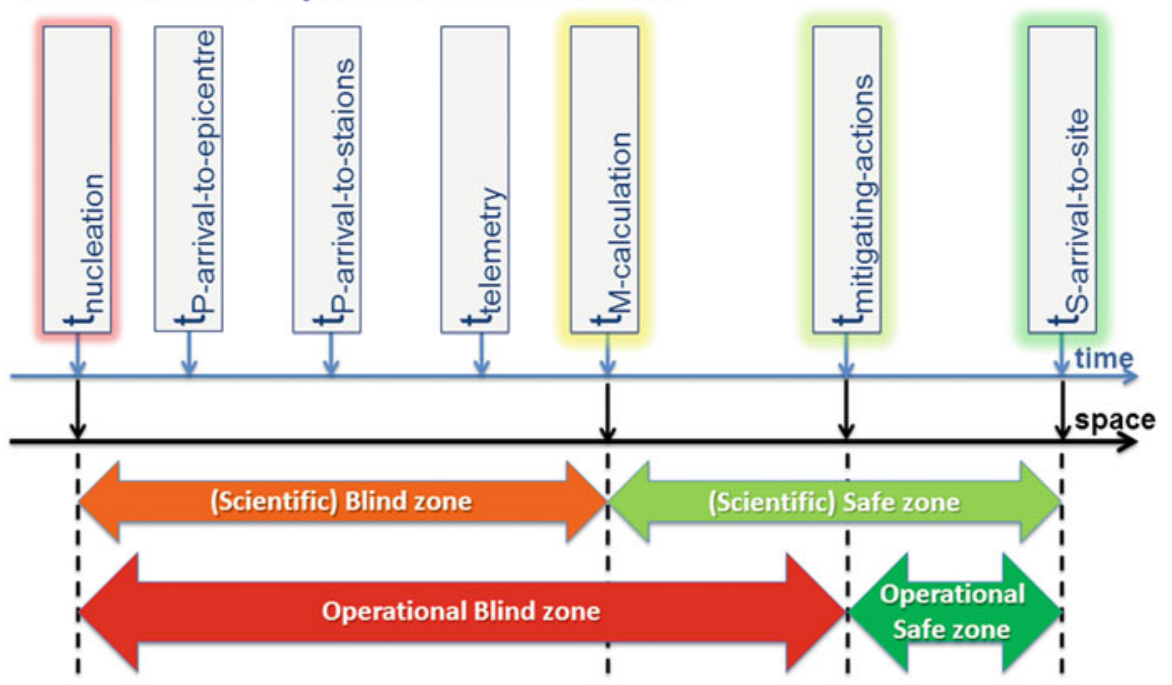

Fig. 2.10 Different definitions of blind and safe zone from the scientific and the operational (civil protection) points of view

- end-users (including population) are educated and trained to receive messages and act consequently and efficiently,

- costs and benefits of the actions are evaluated,

- infrastructures required for automatic actions are efficient,

- downtime is avoided in the links among elements of the EEW chain,

- responsibilities related to false and missed alarms and legal framework are well defined.

A very important point, which is strictly related to the capability of an EEWS to really mitigate risk in real time, is how to identify the so-called "blind zone", where no real-time mitigating action can be carried out, as the information about the impending earthquake arrives too late; and, consequently, how to identify the "safe zone", where potentially some mitigating action can be made (see Fig. 2.10). Actually, defining this latter as a "safe" zone solely on the basis of the above mentioned scientific evaluations can be misleading, because the identification of a "safe" zone should also account for the time needed to undertake a specific "realtime" mitigation action that, obviously, requires from some seconds to some tens of seconds (Goltz 2002). When including also this time interval in the calculation of the "blind zone" radius, a considerable increase occurs, from $30-35 \mathrm{~km}$ to some 50-60 km. Unfortunately, this reduces considerably the effectiveness of the EEWS for Italian earthquakes, which are historically characterized by magnitudes that rarely exceeded 7.0. Dealing with these values, the EEW applicability in the severely damaged zones around the epicentral area is totally excluded, whereas 
the zones of its potential utilization actually correspond to areas where the felt intensity implies no or negligible structural damage.

From a communication perspective, it has to be noticed that spreading a purely scientific information that, though correct, neglects a comprehensive analysis including civil protection issues could determine in the stakeholders and in the general public undue expectations, beyond the actual EEW potential capabilities in Italy, if it is based on a regional approach.

\subsubsection{SHARE}

SHARE - Seismic Hazard Harmonization in Europe (http://www.share-eu.org/) is a Collaborative Project in the Cooperation programme of the EU Seventh Framework Programme. "SHARE's main objective is to provide a community-based seismic hazard model for the Euro-Mediterranean region with update mechanisms. The project aims at establishing new standards in Probabilistic Seismic Hazard Assessment (PSHA) practice by a close cooperation of leading European geologists, seismologists and engineers. ... SHARE produced more than 60 time-independent European Seismic Hazard Maps, spanning spectral ordinates from 0 (PGA) to $10 \mathrm{~s}$ and exceedance probabilities ranging from $10^{-1}$ to $10^{-4}$ yearly probability".

Eighteen scientific partners from thirteen countries contributed to the project, which started on September 2011, with a 3 years duration. No stakeholder acted as end-user. The most renowned product of SHARE is the 475 years return period PGA map of Europe, shown in Fig. 2.11, which reproduces the poster of the project, entitled "European Seismic Hazard Map".

In Italy, the official set of seismic hazard maps is a product of a DPC-INGV project released in 2004 (http://esse1-gis.mi.ingv.it/). These maps were enforced in 2006 (OPCM 3519/2006) and they were included in the current Italian seismic code in 2008 (DM 14 January 2008).

If one compares the two corresponding (475 years return period) PGA hazard maps, as shown in Fig. 2.12, considerable differences in PGA can be observed, with systematically greater values in the SHARE map. Such differences are typically in the order of $+0.10 \mathrm{~g}$ (up to $0.15-0.20 \mathrm{~g}$, locally), resulting in percentage differences reaching $50 \%$ even in high hazard areas (Meletti et al. 2013). Based on this comparison, one could infer that not only is the national official map set "wrong", assuming the most recent being the "right" one, but also highly non-conservative. Therefore, severe doubts about the correctness of the Italian official hazard and classification maps could arise, along with general problems of communication with the general public and the media.

From an engineering viewpoint, on the contrary, spectral accelerations are the only ones that enter into the design procedures and are, therefore, much more important than PGA for seismic risk mitigation. From this perspective, if one looks at the hazard maps in terms of spectral accelerations corresponding to $\mathrm{T}=0.5 \mathrm{~s}$ vibration period, differences of only $\pm 0.05 \mathrm{~g}$ are typically detected (Meletti et al. 2013). Being of opposite signs, these differences highlight that the 


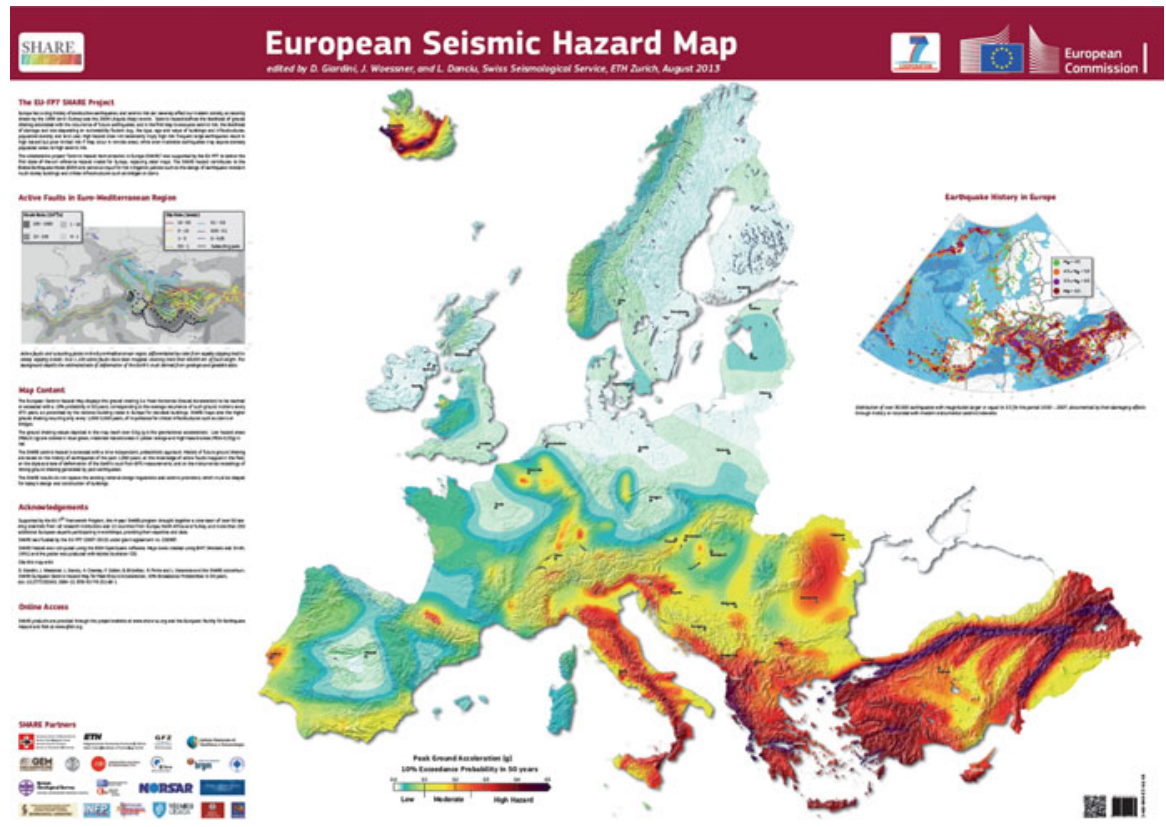

Fig. 2.11 Poster of the SHARE project, which reproduces the 475 return period PGA map of Europe (http://www.share-eu.org/sites/default/files/SHARE_Brochure_public.web_.pdf)
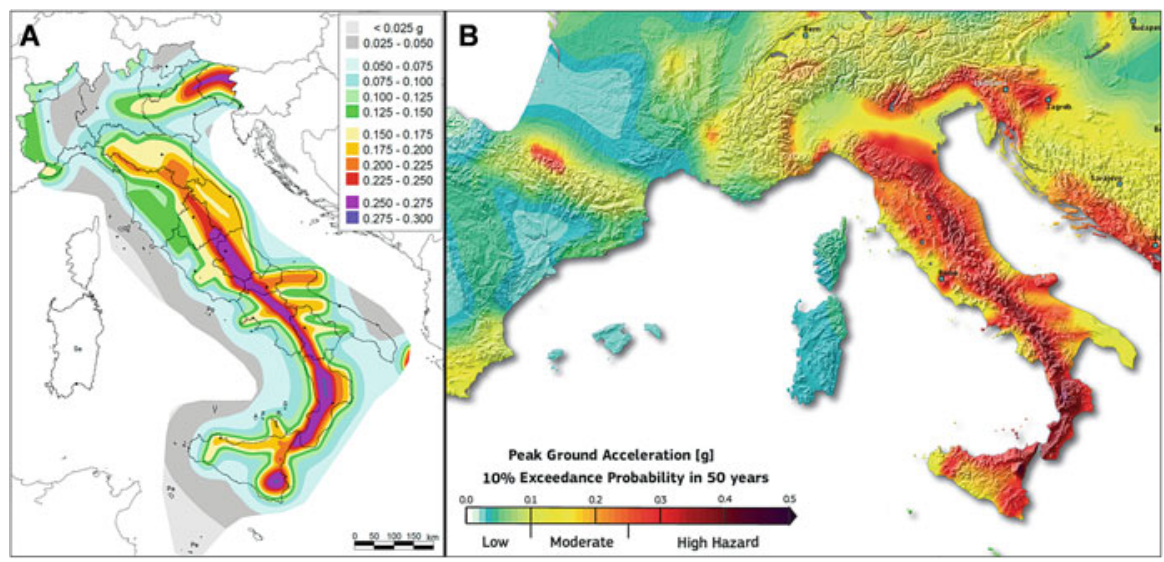

Fig. 2.12 Official (seismic code) PGA hazard map of Italy (a) vs. SHARE PGA hazard map (b) for the same area, referred to $10 \%$ probability in 50 years (Maps are taken, respectively, from: http://zonesismiche.mi.ingv.it/mappa_ps_apr04/italia.html, and http://www.share-eu.org/sites/ default/files/SHARE_Brochure_public.web_.pdf) 
Italian official hazard model is not under-conservative, differently from what the PGA maps would induce to believe, and are instead acceptable from an engineering point of view.

\subsubsection{Free Research Works}

As anticipated in section 3, there is also a large amount of scientific studies and published papers that are independently produced by the scientific community, and sometimes by inventors and amateurs, that could have repercussions on civil protection activities. They are in many cases related to:

- drafting new hazard maps,

- making earthquake predictions (short- and medium-term),

- discovering new active faults (especially in built environments),

- inventing instruments that try to make a sort of earthquake early warning,

- conceiving new structural devices or building techniques,

- inventing antiseismic indoor shelters, like antiseismic boxes, rooms, cellules, beds, etc.

There is a very large number of examples that could be mentioned here, but anyone reading this paper can focalize on his own experience about some of the above situations raising almost daily.

Without discussing the scientific value, sometimes high, of these products made freely available, it is quite clear that their integration in the civil protection procedures or decisional processes cannot be immediate. As a matter of fact, intrinsic in the research activity is the scientific debate on the new findings. Therefore, before a new scientific product can be taken into consideration for civil protection purposes, not only it has to be published on peer reviewed journals, but it has also to be widely and publicly discussed and somehow "accepted" by a large part of the scientific community (also assuming that a $100 \%$ consensus is practically impossible to reach). After this pre-requisite is fulfilled, these scientific results need to be envisaged in the civil protection decisional chain (including a cost-benefit analysis), and in most cases they need to be adapted and calibrated to civil protection operability. Finally, a testing phase follows, aimed at verifying if their use, ultimately, brings advantage in the achievement of the system goals. All these steps stand to reason that civil protection decisions and actions have a strong and direct impact on the society, and thus they have to be undertaken on well-grounded premises.

As one can imagine, this integration process takes time, and therefore it can suffer from some shortcuts followed for instance by individual scientists, who promote the immediate use of their results through the mass media and the political authorities, at both national and local level. No matter if the new findings are the outcome of valuable research or not, when civil protection is improperly urged to promptly acknowledge or adopt some specific new findings and take any useful 
action to mitigate risk based on them, this will cause a damage to the entire system. This problem can be overcome only by increasing the awareness that scientists, media, PDMs and TDMs, all of them compose the same puzzle, and cooperation, interchange, correct communication are the only way to attain the shared goal of a more effective civil protection when working for risk mitigation.

\subsection{Conclusion}

The relationships between science and civil protection, as shown in this paper, are very complex, but they can imply important synergies if correctly addressed. On the one hand, scientific advances can allow for more effective civil protection decisions and actions, although critical issues can arise for the civil protection system, that has to suitably shape its activities and operational procedures according to these advances. On the other hand, the scientific community can benefit from the enlargement of the investigation perspectives, the clear finalisation of the applied research activities and their positive social implications.

In the past decades the main benefits from civil protection-science interaction in Italy were a general growth of interest on Seismology and Earthquake Engineering and a general increase of the amount and of the scientific quality of research in these fields. But there were also a still inadequate finalisation of the products and some inconsistencies of the results not solved within and among the research groups (i.e., lack of consensus).

Progresses recently achieved, consequent to a re-organization effort that started in 2004, encompass:

- better structured scientific activities, finalised to civil protection purposes;

- an improved coordination among research units for the achievement of civil protection objectives;

- the realization of products of ready use (e.g.: tools for hazard analysis, databases in GIS environment, guidelines);

- a substantial increase of experimental investigations, data exchanging and comparisons within large groups, as well as the achievement of a consensus on results, strictly intended for decisional purposes;

- a renewed cooperation in the divulgation activities aimed at increasing risk awareness in the population;

- better structured advisory activities of permanent and special commissions.

While important progresses are registered, a further improvement in the cooperation can be still pursued, and many problems also remain in case of non-structured interactions between civil protection and scientific community.

For all the above reasons, a smart interface between civil protection and scientific community continues to be necessary (Di Bucci and Dolce 2011), in order to identify suitable objectives for the research funded by DPC, able to respond to civil protection needs and consistent with the state-of-the-art at international level. 
After the 2009 L'Aquila and 2012 Emilia earthquakes, the scientific partners have provided a considerable contribution to the National Service of Civil Protection in Italy, not only with regard to the technical management of the emergency but also the divulgation campaigns for the population under the DPC coordination. However, an even more structured involvement of the $\mathrm{CC}$ is envisaged, even in the emergency phase.

The authors strongly believe in the need and the opportunity that the two worlds, scientific community and civil protection, carry on cooperating and developing an interaction capability, focusing on those needs that are a priority for the society and implementing highly synergic relationships, which favour an optimized use of the limited resources available. Some positive examples come from the Italian experience and have been described along with some of the tackled difficulties. They deal with many different themes and are intended to show the multiplicity and diversity of issues that have to be considered in a day-by-day work of interconnection between civil protection and scientific community. These examples can help to get a more in-depth mutual understanding between these two worlds and provide some suggestions and ideas for the audience, national and international, which forms the seismic risk world.

Acknowledgments The Authors are responsible for the contents of this work, which do not necessarily reflect the position and official policy of the Italian Department of Civil Protection.

Open Access This chapter is distributed under the terms of the Creative Commons Attribution Noncommercial License, which permits any noncommercial use, distribution, and reproduction in any medium, provided the original author(s) and source are credited.

\section{References}

AGU Fall Meeting (2012) Lessons learned from the L'Aquila earthquake verdicts press conference. http://www.youtube.com/watch? $\mathrm{v}=\mathrm{xNK} 5 \mathrm{nmDFgy} 8$

Alexander DE (2014a) Communicating earthquake risk to the public: the trial of the "L'Aquila Seven". Nat Hazards. doi:10.1007/s11069-014-1062-2

Alexander DE (2014b) Reply to a comment by Franco Gabrielli and Daniela Di Bucci: "Communicating earthquake risk to the public: the trial of the 'L'Aquila Seven". Nat Hazards. doi:10. 1007/s11069-014-1323-0

Allen CR (1982) Earthquake prediction-1982 overview. Bull Seismol Soc Am 72(6B):S331-S335

Basili R, Valensise G, Vannoli P, Burrato P, Fracassi U, Mariano S, Tiberti MM, Boschi E (2008) The Database of Individual Seismogenic Sources (DISS), version 3: summarizing 20 years of research on Italy's earthquake geology. Tectonophysics. http://dx.doi.org/10.1016/j.tecto. 2007.04.014

Berelson B (1948) Communication and public opinion. In: Schramm W (ed) Communication in modern society. University of Illinois Press, Urbana

Bretton R (2014) The role of science within the rule of law. "Science, uncertainty and decision making in the mitigation of natural risks", Workshop of Cost Action IS1304 "Expert Judgment Network: Bridging the Gap Between Scientific Uncertainty and Evidence-Based Decision Making”. Rome, 8-9-10 Oct 2014. Oral presentation 
D’Ambrogi C, Di Bucci D, Dolce D, Donda F, Ferri F, Improta L, Mucciarelli M, Panei L, Scrocca D, Stabile TA, Vittori E (2014) Tavolo di Lavoro interistituzionale ISPRA. Rapporto sullo stato delle conoscenze riguardo alle possibili relazioni tra attività antropiche e sismicità indotta/innescata in Italia. ISPRA. http://www.isprambiente.gov.it/it/news/rapporto-sullostato-delle-conoscenze-riguardo-alle-possibili-relazioni-tra-attivita-antropiche-e-sismicitaindotta-innescata-in-italia. 27 June 2014

Di Bucci D, Dolce M (2011) Research projects in seismology funded by the Italian Department of Civil Protection. DVD e Volume degli atti della "First Sino Italian Conference on: Advanced Methodologies and Technologies in Geophysics, Geodynamics and Seismic Hazard Assessment". Pechino, 29-30 Marzo 2010, pp 43-45

Dipartimento della Protezione Civile and Fondazione CIMA (DPC and CIMA) (eds) (2013) Protezione Civile e responsabilità nella società del rischio. Chi valuta, chi decide, chi giudica (Civil protection and responsibilities in the risk society. Who evaluates, who decides, who judges). ETS Editor, p 152

Dipartimento della Protezione Civile and Fondazione CIMA (DPC and CIMA) (eds) (2014) La Protezione Civile nella società del rischio. Procedure, Garanzie, Responsabilità (Civil protection in the risk society. Procedures, guarantees, responsibilities) ETS Editor, p 92

DISS Working Group (2010) Database of Individual Seismogenic Sources (DISS), Version 3.1.1: a compilation of potential sources for earthquakes larger than M 5.5 in Italy and surrounding areas. http://diss.rm.ingv.it/diss/, (C) INGV 2010 - Istituto Nazionale di Geofisica e Vulcanologia - All rights reserved; doi:10.6092/INGV.IT-DISS3.1.1

Dolce M (2008) Civil protection vs. earthquake engineering and seismological research, Proceeding of 14th world conference on earthquake engineering, Oct 2008, Beijing, Keynote speech

Dolce M, Di Bucci D (2014) Risk management: roles and responsibilities in the decision-making process. In: Peppoloni S, Wyss M (eds) Geoethics: ethical challenges and case studies in earth science. Section IV: Communication with the public, officials and the media, Chapter 18. Elsevier. Publication Date: 21 Nov 2014 | ISBN-10: 0127999353 | ISBN-13: 978-0127999357 I Edition: 1

Gabrielli F (2013) Preface in: Dipartimento della Protezione Civile and Fondazione CIMA (DPC and CIMA) (eds), 2013. Protezione Civile e responsabilità nella società del rischio. Chi valuta, chi decide, chi giudica (Civil protection and responsibilities in the risk society. Who evaluates, who decides, who judges). ETS Editor, pp 3-10

Gabrielli F, Di Bucci D (2014) Comment on "communicating earthquake risk to the public: the trial of the 'L'Aquila Seven" by David E. Alexander. Nat Hazards. doi:10.1007/s11069-0141322-1. Published online: 19.07.2014

Gasparini P (2013) Natural hazards and scientific advice: interactions among scientists, decision makers and the public. Plenary Lecture, 2013 Goldschmidt Conference (Florence, Italy). Mineral Mag 77(5):1146

Goltz JD (2002) Introducing earthquake early warning in California: a summary of social science and public policy issues, technical report, Governor's Off. of Emergency Serv., Pasadena

HORIZON 2020, Work Programme 2014-2015. 14. Secure societies - protecting freedom and security of Europe and its citizens. European Commission Decision C (2014) 4995 of 22 July 2014. http://ec.europa.eu/research/participants/data/ref/h2020/wp/2014_2015/main/h2020wp1415-security_en.pdf

Jordan T, Chen Y, Gasparini P, Madariaga R, Main I, Marzocchi W, Papadopoulos G, Sobolev G, Yamaoka K, Zschau J (2011) Operational earthquake forecasting. State of knowledge and guidelines for utilization. Ann Geophys 54(4). doi:10.4401/ag-5350

Jordan TH, Marzocchi W, Michael AJ, Gerstenberger MC (2014) Operational earthquake forecasting can enhance earthquake preparedness. Seismol Res Lett 85(5):955-959

Luzi L, Hailemikael S, Bindi DD, Pacor F, Mele F, Sabetta F (2008) ITACA (ITalian ACcelerometric Archive): a web portal for the dissemination of Italian strong-motion data. Seismol Res Lett 79(5):716-722. doi:10.1785/gssrl.79.5.716 
Manfredi G, Dolce M (eds) (2009) The state of the art of earthquake engineering research in Italy: the ReLUIS-DPC 2005-2008 Project, Doppiavoce, Napoli. http://www.reluis.it/CD/ReLUISDPC/ReLUIS-DPC.htm

Mele F, Riposati D (2007) ISIDe, Italian Seismological Instrumental and parametric Data-basE. GNGTS 2007

Meletti C, Rovida A, D'Amico V, Stucchi M (2013) Seismic hazard models for the Italian area: "MPS04-S1" and "SHARE", Progettazione Sismica - Vol. 5, N. 1, Anno 2014. doi:10.7414/ PS.5.1.15-25 - http://dx.medra.org/10.7414/PS.5.1.15-25

Mucciarelli M (2014) Some comments on the first degree sentence of the "L'Aquila trial". In: Peppoloni S, Wyss M (eds) Geoethics: ethical challenges and case studies in earth science. Elsevier. Publication Date: 21 Nov 2014 | ISBN-10: 0127999353 | ISBN-13: 978-0127999357 I Edition: 1

Pacor F, Paolucci R, Luzi L, Sabetta F, Spinelli A, Gorini A, Marcucci S, Nicoletti M, Filippi L, Dolce M (2011) Overview of the Italian strong motion database ITACA 1.0. Bull Earthq Eng 9 (6):1723-1739. doi:10.1007/s10518-011-9327-6, Springer Ltd, Dordrecht, The Netherlands

Picozzi M, Zollo A, Brondi P, Colombelli S, Elia L, Martino C (2014) Exploring the feasibility of a nation-wide earthquake early warning system in Italy, First draft of the final report for the REAKT Project

Pitilakis K, Crowley E, Kaynia A (eds) (2014a) SYNER-G: typology definition and fragility functions for physical elements at seismic risk, vol 27, Geotechnical, geological and earthquake engineering. Springer Science + Business Media, Dordrecht. ISBN 978-94-007-7872-6

Pitilakis K, Franchin P, Khazai B, Wenzel H (eds) (2014b) SYNER-G: systemic seismic vulnerability and risk assessment of complex urban, utility, lifeline systems and critical facilities, vol 31, Geotechnical, geological and earthquake engineering. Springer Science + Business Media, Dordrecht. ISBN 978-94-017-8835-9

Satriano C, Elia L, Martino C, Lancieri M, Zollo A, Iannaccone G (2010) PRESTo, the earthquake early warning system for southern Italy: concepts, capabilities and future perspectives. Soil Dyn Earthq Eng. doi:10.1016/j.soildyn.2010.06.008

Schramm W (1954) How communication works. In: Schramm W (ed) The process and effects of mass communication. University of Illinois Press, Urbana

Zuccaro G, De Gregorio D, Dolce M, Speranza E, Moroni C (2014) Manuale per la compilazione della scheda di $1^{\circ}$ livello per la caratterizzazione tipologico-strutturale dei comparti urbani costituiti da edifici ordinari (Manual for the compilation of the 1st level form to characterize urban districts with respect to the structural types of ordinary building), preliminary draft. ReLUIS 